\title{
Cell Type-Specific Decrease of the Intrinsic Excitability of Motor Cortical Pyramidal Neurons in Parkinsonism
}

\author{
Liqiang Chen, Samuel Daniels, Yerim Kim, and ${ }^{\circledR}$ Hong-Yuan Chu \\ Department of Neurodegenerative Science, Van Andel Institute, Grand Rapids, Michigan 49503
}

The hypokinetic motor symptoms of Parkinson's disease (PD) are closely linked with a decreased motor cortical output as a consequence of elevated basal ganglia inhibition. However, whether and how the loss of dopamine (DA) alters the cellular properties of motor cortical neurons in PD remains undefined. We induced parkinsonism in adult C57BL/6 mice of both sexes by injecting neurotoxin, 6-hydroxydopamine (6-OHDA), into the medial forebrain bundle. By using ex vivo patch-clamp recording and retrograde tracing approach, we found that the intrinsic excitability of pyramidal tract neurons (PTNs) in the primary motor cortical (M1) layer (L)5b was greatly decreased in parkinsonism; but the intratelencephalic neurons (ITNs) were not affected. The cell type-specific intrinsic adaptations were associated with a depolarized threshold and broadened width of action potentials (APs) in PTNs. Moreover, the loss of midbrain dopaminergic neurons impaired the capability of M1 PTNs to sustain high-frequency firing, which could underlie their abnormal pattern of activity in the parkinsonian state. We also showed that the decreased excitability in parkinsonism was caused by an impaired function of both persistent sodium channels and the large conductance, $\mathrm{Ca}^{2+}$-activated $\mathrm{K}^{+}$channels. Acute activation of dopaminergic receptors failed to rescue the impaired intrinsic excitability of M1 PTNs in parkinsonian mice. Altogether, our data demonstrated a cell typespecific decrease of the excitability of M1 pyramidal neurons in parkinsonism. Thus, intrinsic adaptations in the motor cortex provide novel insight in our understanding of the pathophysiology of motor deficits in PD.

Key words: basal ganglia; dopamine; electrophysiology; intrinsic plasticity; motor cortex; Parkinson's disease

\section{Significance Statement}

The degeneration of midbrain dopaminergic neurons in Parkinson's disease (PD) remodels the connectivity and function of cortico-basal ganglia-thalamocortical network. However, whether and how dopaminergic degeneration and the associated basal ganglia dysfunction alter motor cortical circuitry remain undefined. We found that pyramidal neurons in the layer $(\mathrm{L})$ $5 \mathbf{b}$ of the primary motor cortex (M1) exhibit distinct adaptations in response to the loss of midbrain dopaminergic neurons, depending on their long-range projections. Besides the decreased thalamocortical synaptic excitation as proposed by the classical model of Parkinson's pathophysiology, these results, for the first time, show novel cellular and molecular mechanisms underlying the abnormal motor cortical output in parkinsonism.

\section{Introduction}

The degeneration of dopamine (DA) neurons in the substantia nigra (SN) alters the connection and computation of cortico-basal ganglia-thalamocortical network, which underlies the devastating motor symptoms in Parkinson's disease (PD), including akinesia, bradykinesia, and rigidity (Albin et al., 1989; Galvan

Received Oct. 20, 2020; revised May 3, 2021; accepted May 5, 2021.

Author contributions: H.-Y.C. designed research; H.-Y.C., L.C., Y.K., and S.D. performed research; H.-Y.C., L.C., Y.K., and S.D. analyzed data; H.-Y.C. wrote the paper.

This work was supported by the National Institute of Neurological Disorders and Stroke Grant R01NS121371 and the startup fund from Van Andel Institute (H.-Y.C). We thank Mr. David Nadziejka from Van Andel Institute for technical editing, the optical imaging core of the Van Andel Research Institute for the advanced confocal microscopy, and the staff of the vivarium of Van Andel Institute for animal care.

The authors declare no competing financial interests.

Correspondence should be addressed to Hong-Yuan Chu at hongyuan.chu@vai.org.

https://doi.org/10.1523/JNEUROSCI.2694-20.2021

Copyright $\odot 2021$ the authors and Wichmann, 2008; McGregor and Nelson, 2019). Specially, the loss of SN DA neurons increases and decreases the activities of indirect and direct pathways, respectively, which disrupts the balanced activity between striatal direct and indirect pathways, leading to the hypokinetic symptoms in PD (Albin et al., 1989; DeLong, 1990). The pathway-specific alterations in the striatum following the loss of SN DA neurons induce numerous cellular and synaptic changes in the basal ganglia nuclei and extended brain regions, which further drive the abnormal neural activity throughout the cortico-basal ganglia-thalamocortical network in parkinsonism (Gittis et al., 2011; Kita and Kita, 2011; Fieblinger et al., 2014; Chu et al., 2015, 2017; Mathai et al., 2015; Shen et al., 2015; Parker et al., 2016, 2018; Sharott et al., 2017; McIver et al., 2019; Willard et al., 2019).

The primary motor cortex (M1) plays essential and complex roles in motor control and motor learning and is a key node in the cortico-basal ganglia-thalamocortical network (Shepherd, 
2013; Ebbesen and Brecht, 2017; Ebbesen et al., 2018). M1 is a laminar structure and contains a heterogeneous group of neurons that differ in gene expression, morphology, connectivity, and electrophysiological properties (Sheets et al., 2011; Oswald et al., 2013; Shepherd, 2013; Suter et al., 2013; Economo et al., 2018). These neurons can be classified into the intratelencephalic neurons (ITNs) distributed across the layer (L)2-L6 and the pyramidal tract neurons (PTNs) that mainly locate within the L5b (Oswald et al., 2013; Shepherd, 2013). Both PTNs and ITNs project to the striatum and receive basal ganglia feedbacks through the transition of the motor thalamus (Bodor et al., 2008; Kita and Kita, 2011; Kress et al., 2013; Lee et al., 2020). In physiological state, M1 network dynamics plays an essential role in the execution and coordination of complex movements and the acquisition of motor skills (Guo et al., 2015a; Kawai et al., 2015; Sreenivasan et al., 2016; Barthas and Kwan, 2017; Ebbesen et al., 2017; Wang et al., 2017; Economo et al., 2018; Sauerbrei et al., 2020). In parkinsonian state, M1 exhibits an aberrant oscillation and bursting pattern of activity at both individual neuron and population levels (Goldberg et al., 2002; Mallet et al., 2008; Pasquereau and Turner, 2011; Shimamoto et al., 2013; de Hemptinne et al., 2015; Pasquereau et al., 2016), which disrupt its normal function in motor control and motor learning.

The abnormal neuronal activity in the M1 has been hypothesized to be a consequence of pathologic basal ganglia output (Hosp et al., 2011, 2015; Pasquereau and Turner, 2011; Guo et al., 2015b; Pasquereau et al., 2016), but the cellular adaptations could also play a role in such abnormal activities. Moreover, compelling evidence suggests that PTNs and ITNs adapt differently to the degeneration of midbrain DA neurons (Pasquereau and Turner, 2011; Pasquereau et al., 2016). However, the cellular and synaptic mechanisms of such adaptations remain unknown. We hypothesized that loss of SN DA neurons alters the intrinsic properties of M1 pyramidal neurons in a cell type-specific manner, which can contribute to the abnormal neuronal activity of M1 in parkinsonism. We addressed these hypotheses using electrophysiology and retrograde tracing approach in mice with 6hydroxydopamine (6-OHDA) lesion, an established model of parkinsonism.

\section{Materials and Methods \\ Animals}

Adult (three to four months old) C57BL/6 mice of both sexes were used in the study. Mice were housed up to four animals per cage under a 12/ $12 \mathrm{~h} \mathrm{light/dark} \mathrm{cycle} \mathrm{with} \mathrm{access} \mathrm{to} \mathrm{food} \mathrm{and} \mathrm{water} \mathrm{ad} \mathrm{libitum} \mathrm{in} \mathrm{accord-}$ ance with Van Andel Institute IACUC and NIH guidelines for care and use of animals. All the animal experiments were reviewed and approved by IACUC at Van Andel Institute.

\section{Stereotaxic surgery}

Mice, under $2 \%$ isoflurane anesthesia, were placed in a stereotaxic frame (Kopf), and were supported by a thermostatic heating pad. To induce degeneration of SN DA neurons, 6-OHDA (3-4 mg/ml, $1.0 \mu \mathrm{l})$ was injected unilaterally into the medial forebrain bundle (MFB; from bregma: anteroposterior, $-0.7 \mathrm{~mm}$; mediolateral, $+1.2 \mathrm{~mm}$; dorsoventral, $-4.7 \mathrm{~mm}$ ) over $10 \mathrm{~min}$ using a $10-\mu \mathrm{l}$ syringe (Hamilton) and a motorized microinjector (Stoelting; Chu et al., 2017). Controls were injected in the same location with vehicle. Desipramine $(25 \mathrm{mg} / \mathrm{kg})$ and pargyline $(50 \mathrm{mg} / \mathrm{kg})$ were subcutaneously injected $30-40 \mathrm{~min}$ before 6OHDA injection, to enhance the toxicity of 6-OHDA on dopaminergic neurons and reduce damages to noradrenergic system (Chu et al., 2015, 2017). To label and identify PTNs and ITNs in the M1, animals also received red or green Retrobeads $(0.3 \mu \mathrm{l}$, Lumafluor Inc) injected into the ipsilateral pontine nuclei (from bregma: anteroposterior, $-5.0 \mathrm{~mm}$; mediolateral, $+0.6 \mathrm{~mm}$; dorsoventral, $-5.0 \mathrm{~mm} ; 0.3 \mu$ l per injection) or the contralateral dorsolateral striatum (from bregma: anteroposterior, $+0.4 \mathrm{~mm}$; mediolateral, $-2.0 \mathrm{~mm}$; dorsoventral, $-2.8 \mathrm{~mm}$ ). The surgical wound was closed using sutures and mice were allowed to recover after surgery in a heated cage with access to food and water at the cage-floor level. Coronal brain sections containing the forelimb region of M1 from 6-OHDA-injected or vehicle-injected mice were prepared three to four weeks after surgery for ex vivo electrophysiology.

\section{Slice preparation}

Mice were deeply anesthetized with intraperitoneal avertin (250 $300 \mathrm{mg} / \mathrm{kg}$ ) and then were perfused transcardially with ice-cold, sucrose-based, artificial CSF (aCSF) containing $230 \mathrm{~mm}$ sucrose, 26 mм $\mathrm{NaHCO}_{3}, 10 \mathrm{~mm}$ glucose, $10 \mathrm{~mm} \mathrm{MgSO}_{4}, 2.5 \mathrm{~mm} \mathrm{KCl}, 1.25 \mathrm{~mm}$ $\mathrm{NaH}_{2} \mathrm{PO}_{4}$, and $0.5 \mathrm{~mm} \mathrm{CaCl}$. Next, coronal brain slices $(250 \mu \mathrm{m})$ containing $\mathrm{M} 1$ forelimb regions were prepared in the same slicing solution using a vibratome (VT1200S; Leica Microsystems Inc.). Brain slices were kept in normal aCSF $(126 \mathrm{~mm} \mathrm{NaCl}, 26 \mathrm{~mm}$ $\mathrm{NaHCO}_{3}, 10 \mathrm{~mm}$ glucose, $2.5 \mathrm{~mm} \mathrm{KCl}, 2 \mathrm{~mm} \mathrm{CaCl}_{2}, 2 \mathrm{~mm} \mathrm{MgSO}_{4}$, $1.25 \mathrm{~mm} \mathrm{NaH}_{2} \mathrm{PO}_{4}, 1 \mathrm{~mm}$ sodium pyruvate, and $0.005 \mathrm{~mm} \mathrm{~L}$-glutathione) equilibrated with $95 \% \mathrm{O}_{2}$ and $5 \% \mathrm{CO}_{2}$ for $30 \mathrm{~min}$ at $35^{\circ} \mathrm{C}$ and then held at room temperature (RT) for $30 \mathrm{~min}$. Electrophysiological recordings started after this 1 -h recovery period.

\section{Ex vivo electrophysiology recording}

Brain slices were transferred into a recording chamber perfused at a rate of $4 \mathrm{ml} / \mathrm{min}$ with synthetic interstitial fluid $(126 \mathrm{~mm} \mathrm{NaCl}, 26 \mathrm{~mm}$ $\mathrm{NaHCO}_{3}, 10 \mathrm{~mm}$ glucose, $3 \mathrm{~mm} \mathrm{KCl}, 1.6 \mathrm{~mm} \mathrm{CaCl}_{2}, 1.5 \mathrm{~mm} \mathrm{MgSO}_{4}$, and $1.25 \mathrm{~mm} \mathrm{NaH}_{2} \mathrm{PO}_{4}$ ) equilibrated with $95 \% \mathrm{O}_{2}$ and $5 \% \mathrm{CO}_{2}$ at $35^{\circ} \mathrm{C}$ via a feedback-controlled in-line heater (TC-324C, Warner Instruments). DNQX $(20 \mu \mathrm{M}), \mathrm{D}-\mathrm{APV}(50 \mu \mathrm{M})$, and SR-95531 $(10 \mu \mathrm{M})$ were routinely added to block synaptic transmission mediated by ionotropic glutamatergic and GABAergic receptors. Neurons were visualized and recorded under gradient contrast SliceScope 6000 (Scientifica) with infrared illumination using a CCD camera (SciCam Pro, Scientifica) and motorized micromanipulators (Scientifica). Individual neurons labeled with Retrobeads in the M1 L5b were identified using a $60 \times$ water immersion objective lens (Olympus) and targeted for whole-cell patchclamp recording, using a MultiClamp 700B amplifier and a Digidata 1550B digitizer under the control of pClamp11 (Molecular Devices). Data were collected at a sampling rate of $20-50 \mathrm{kHz}$. Borosilicate glass pipettes (O.D. $=1.5 \mathrm{~mm}$, I.D. $=0.86 \mathrm{~mm}$, item \#BF150-86-10, Sutter Instruments) for patch clamp recordings (4-7 $M \Omega$ ) were pulled using a micropipette puller (P1000, Sutter Instruments). Pipette capacitance was compensated for before the formation of the whole-cell configuration. Series resistance (Rs) was regularly monitored and compensated for with the bridge balance circuit in current clamp mode. Liquid junction potential $(\sim 11 \mathrm{mV})$ was corrected. Under current clamp mode, pipette capacitance was neutralized using MultiClamp 700B amplifier. Briefly, $\sim 10$ $\mathrm{mV}$ sawtooth pattern of voltage trace was generated through "tuning" function. Then, the degree of capacitance neutralization was determined by gradually increasing capacitance values until voltage oscillations were about to onset. Under these conditions, the averaged value of pipette capacitance neutralization was $3.3 \pm 0.07 \mathrm{pF}$.

Retrobeads-labeled neurons in the L5b of M1 were recorded in whole-cell current-clamp mode to study their intrinsic properties. In these experiments, glass pipettes were filled with a potassium gluconatebased internal solution of $140 \mathrm{~mm}$ K-gluconate, $3.8 \mathrm{~mm} \mathrm{NaCl}, 1 \mathrm{~mm}$ $\mathrm{MgCl}_{2}$, $10 \mathrm{~mm}$ HEPES, $0.1 \mathrm{~mm} \mathrm{Na}$-EGTA, $2 \mathrm{~mm}$ ATP-Mg, and $0.1 \mathrm{~mm}$ GTP-Na, pH 7.3, osmolarity 290 mOsm. The resting membrane potential $\left(\mathrm{V}_{\mathrm{m}}\right)$ was recorded once the whole-cell configuration was obtained. The intrinsic properties and excitability of M1 pyramidal neuron subtypes were studied by injecting a family of current steps ranging from -240 to $720 \mathrm{pA}$ in $40-\mathrm{pA}$ increments and with a duration of $1 \mathrm{~s}$. Current injections were from $\mathrm{V}_{\mathrm{m}}$ and no additional holding current was injected. Input resistance $\left(\mathrm{R}_{\mathrm{m}}\right)$ was determined by measuring the steady-state voltage responses to a series of 1-s hyperpolarizing currents, as the slope of linear fit to the resulting voltage-current relationship. The membrane time constant $\left(\tau_{\mathrm{m}}\right)$ was determined as the slow component of a doubleexponential fit of the voltage decays in response to -40 or $-80 \mathrm{pA}, 1$-s 
A

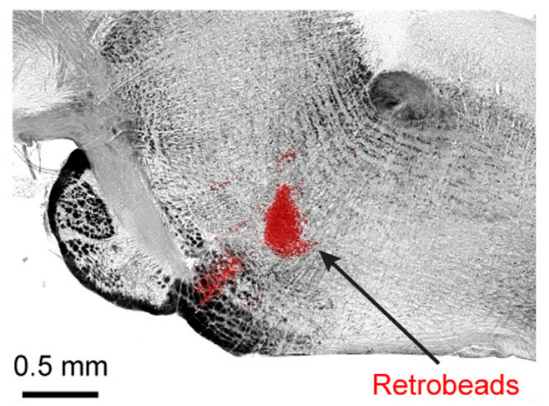

B
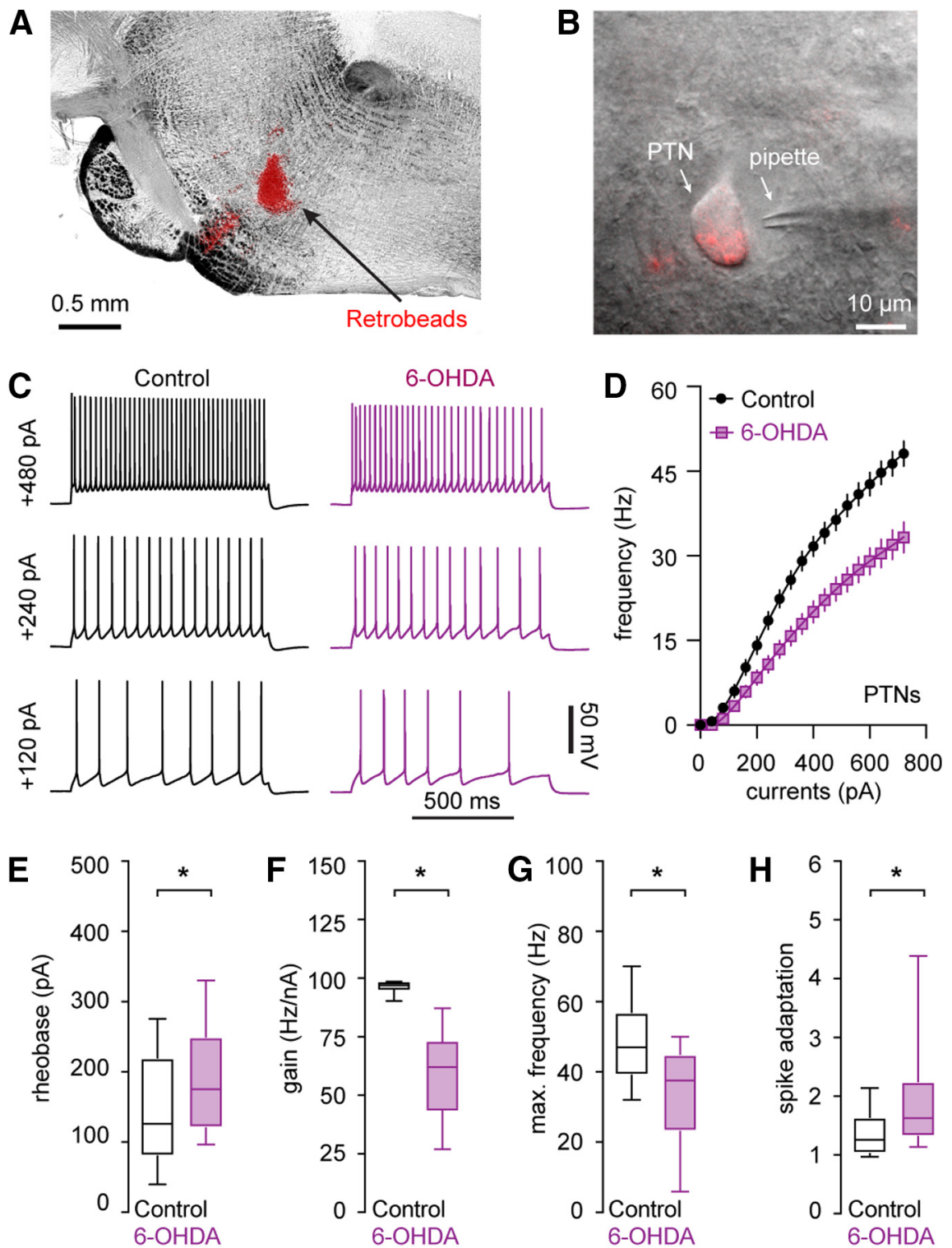

Figure 1. Decreased intrinsic excitability of PTNs in the L5b of M1 following the loss of midbrain DA neurons. $\boldsymbol{A}, \boldsymbol{B}$ Representative graphs showing the injection site of red Retrobeads in the pontine nuclei $(\boldsymbol{A})$ and a retrogradely labeled PTN in L5b of M1 $(\boldsymbol{B}) . \boldsymbol{C}, \boldsymbol{D}$, Representative spike trains of PTNs evoked by somatic current injections from controls and 6-OHDA mice $(\boldsymbol{C})$ and the frequency-current relationship of the PTNs from controls and 6-OHDA mice $(\boldsymbol{D})$. $\boldsymbol{E}-\boldsymbol{H}$, Summarized results showing an increased rheobase $(\boldsymbol{E})$, a reduced gain of spike-current curve $(\boldsymbol{F})$, a decreased firing frequency in response to maximal current injections (i.e., $720 \mathrm{pA} ; \boldsymbol{G}$ ), and an enhanced spike adaptation $(\boldsymbol{H})$ in PTNs from 6-OHDA mice relative to those from controls; ${ }^{*} p<0.05$, MWU.

current injections (i.e., a 5- to $10-\mathrm{mV}$ voltage change). Cell capacitance $\left(C_{m}\right)$ was derived from the equation $C_{m}=\tau_{m} / R_{m}$.

The rheobase, as an indicator of neuronal excitability, was defined as the current intensity to elicit an action potential (AP). Rheobase was determined by first probing the response of neurons to 1-s current injections to define the targeted range of current intensities, and then by bounding the rheobase through small current steps (1-pA increments). AP waveforms at the rheobase were systematically analyzed and quantified using Clampfit 11.1. Specifically, the threshold of AP was determined as the voltage level at which $\mathrm{d} V / \mathrm{d} t$ exceeded $20 \mathrm{mV} / \mathrm{ms}$. AP amplitude was defined as the voltage difference between the threshold and the peak voltage. AP half-width was measured as the time difference at $50 \%$ of AP amplitude. Fast afterhyperpolarizations (fAHPs) were measured as the negative voltage peaks relative to the threshold within 2-5 ms from AP threshold (Villalobos et al., 2004; Bean, 2007). To quantify spike trains, spike frequency adaptation was measured as the ratio between the last interspike interval and the average of the first two

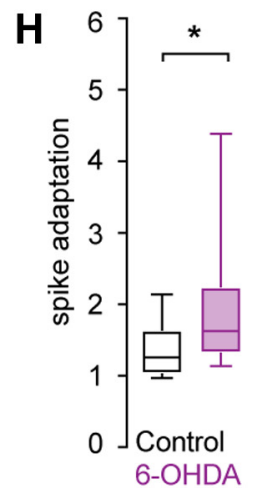

interspike intervals. The gain of the spike-current curve was defined as the slope of the linear portion of the instantaneous spike-current curve.

\section{Immunohistochemistry}

Immunoreactivity of tyrosine hydroxylase (TH) and norepinephrine transporter (NET) was assessed to validate the degeneration of the nigrostriatal DA projections and noradrenergic projections to M1 in 6-OHDA-injected mice. Briefly, brain tissues were first fixed in $4 \%$ paraformaldehyde in $0.1 \mathrm{M}$ phosphate buffer, $\mathrm{pH} 7.4$, at $4^{\circ} \mathrm{C}$ for $12 \mathrm{~h}$ before rinsing in PBS (0.05 M; pH 7.4). Tissues was re-sectioned at $70 \mu \mathrm{m}$ using a vibratome (Leica VT1000S; Microsystems Inc.). Immunochemical detection of TH was conducted in PBS containing $0.2 \%$ Triton X-100 (Fisher Scientific) and 2\% normal donkey serum (Sigma-Aldrich). Brain sections were incubated in primary antibody (mouse anti-TH antibody, 1:2000, catalog \#MAB318, Sigma-Aldrich; or mouse anti-NET antibody, 1:1000, catalog \#211463, Abcam) for $48 \mathrm{~h}$ at $4^{\circ} \mathrm{C}$ or overnight at RT, washed in PBS, and then incubated in the secondary antibody (donkey anti-mouse Alexa Fluor 488, catalog \#715-545-150 or donkey anti-mouse Alexa Fluor 594, catalog \#715-585-150; 1:500, Jackson ImmunoReseach) for $90 \mathrm{~min}$ at RT before washing with PBS. Brain sections were mounted on glass slides using VECTASHIELD antifade mounting medium (catalog \#H-1000, Vector Laboratories) and were cover-slipped. TH immunoreactivity in the dorsal striatum and the overlying motor cortex in the same section was imaged using an Olympus BX63F microscope equipped with an Olympus DP80 camera or a confocal laser scanning microscope (A1R; Nikon). TH-immunoreactivity (TH-ir) of each section was determined as the difference between the immunofluorescence between the dorsal striatum and the motor cortex (Chu et al., 2015). The intensity of TH and NET immunofluorescence was quantified using ImageJ (NIH).

\section{Animal behavior}

To validate the development of parkinsonian bradykinesia and akinesia before electrophysiology studies, vehicle-injected and 6-OHDAinjected mice were subject to (1) open field locomotion test for $10 \mathrm{~min}$ and their locomotor activity and rotations were monitored and quantified using Anymaze software (Stoelting); (2) cylinder test to assess their spontaneous forelimbs use during weight-bearing touch on wall of a 600 -ml glass cylinder. Spontaneous exploration of mice was recorded using an HD digital camcorder at $60 \mathrm{fps}$ (Panasonic, HC-V180K) and analyzed off-line by a researcher blinded to treatments.

\section{Experimental design and statistical analysis}

Data were analyzed in Clampfit 11.1 (Molecular Devices) and ImageJ (NIH). Statistics were done using Prism8 (GraphPad Software). To minimize the assumption of the data normality, we used non-parametric, distribution-independent Mann-Whiney $U$ (MWU) or Wilcoxon signedrank (WSR) tests for non-paired or paired data comparisons, respectively. The Holm-Bonferroni correction was applied for multiple comparisons. All tests were two-tailed, and an $\alpha$-level of 0.05 was used to determine statistical significance. Results are reported as median and 
interquartile range. Boxplots illustrate the median (central line), interquartile range (box), and $10-90 \%$ range (whiskers) of data. Data are available on request.

\section{Results}

All physiology studies were conducted between three and four weeks postsurgery, when the level of midbrain DA degeneration and functional adaptations in the brain have reached maximum and been stabilized (Vila et al., 2000; Viaro et al., 2011). At three weeks postsurgery, mice with 6-OHDA lesion (hereinafter, "6OHDA mice") showed featured parkinsonians akinesia and bradykinesia versus vehicle-injected controls (hereinafter, "controls"), as supported by (1) a reduced traveled distance in open-field locomotion test (6OHDA mice $=18[16,22] \mathrm{m}$, controls $=41$ $[32,50] \mathrm{m}, n=13$ mice from each group, $p<0.0001, \mathrm{MWU})$; (2) ipsilateral rotations (\%ipsilateral rotations, 6-OHDA mice $=100$ $[97,100] \%$, controls $=41[26,53] \%, n=13$ mice from each group, $p<0.0001$, MWU); and (3) impaired forelimb use (\%ipsilateral forelimb use: 6-OHDA mice $=88[83,92] \%$, controls $=50 \quad[49,53] \%, n=13$ mice from each group, $p<0.0001, \mathrm{MWU})$. In post hoc histology studies, 6-OHDA mice showed $>80 \%$ reduction of striatal $\mathrm{TH}$-ir in the hemisphere with lesion (\% $\mathrm{TH}$-ir in the ipsilateral vs the contralateral striatum, 6-OHDA mice $=0[0,0] \%$, and controls $=97[85,102] \%, n=16$ mice for each group). In addition, desipramine was routinely administered to inhibit reuptake of 6-OHDA by noradrenergic terminals. Given the heavy noradrenergic innervation of the cortical regions, we therefore validated the effect of desipramine by immunostaining of cortical NET and striatal $\mathrm{TH}$ in a separate cohort of animals. \%NET-ir in the ipsilateral versus contralateral L5 of M1, 6-OHDA = 92 [78, $108] \%$, while $\% \mathrm{TH}$-ir in the ipsilateral versus contralateral striatum $=0[0,3.5] \%$, $n=8$ sections $/ 4$ mice.

\section{Cell type-specific decrease in the intrinsic excitability of M1} L5b pyramidal neurons following the loss of midbrain DA neurons

We compared the intrinsic excitability of projection-defined pyramidal neurons in the L5b of M1 from controls and 6-OHDA mice. To identify M1 pyramidal neurons based on long-range projections, Retrobeads were stereotaxically injected into the ipsilateral pontine nuclei (Fig. $1 A$ ) and the contralateral striatum (Fig. 2A) to retrogradely label PTNs (Fig. $1 B$ ) and ITNs (Fig. 2B), respectively. The intrinsic electrophysiological properties of M1 PTNs and ITNs were assessed using whole-cell current-clamp recording in the presence of antagonists of ionotropic glutamatergic and GABAergic receptors, including DNQX (20 $\mu \mathrm{M}), \mathrm{D}-\mathrm{APV}$ $(50 \mu \mathrm{M})$, and SR95531 $(10 \mu \mathrm{M})$.
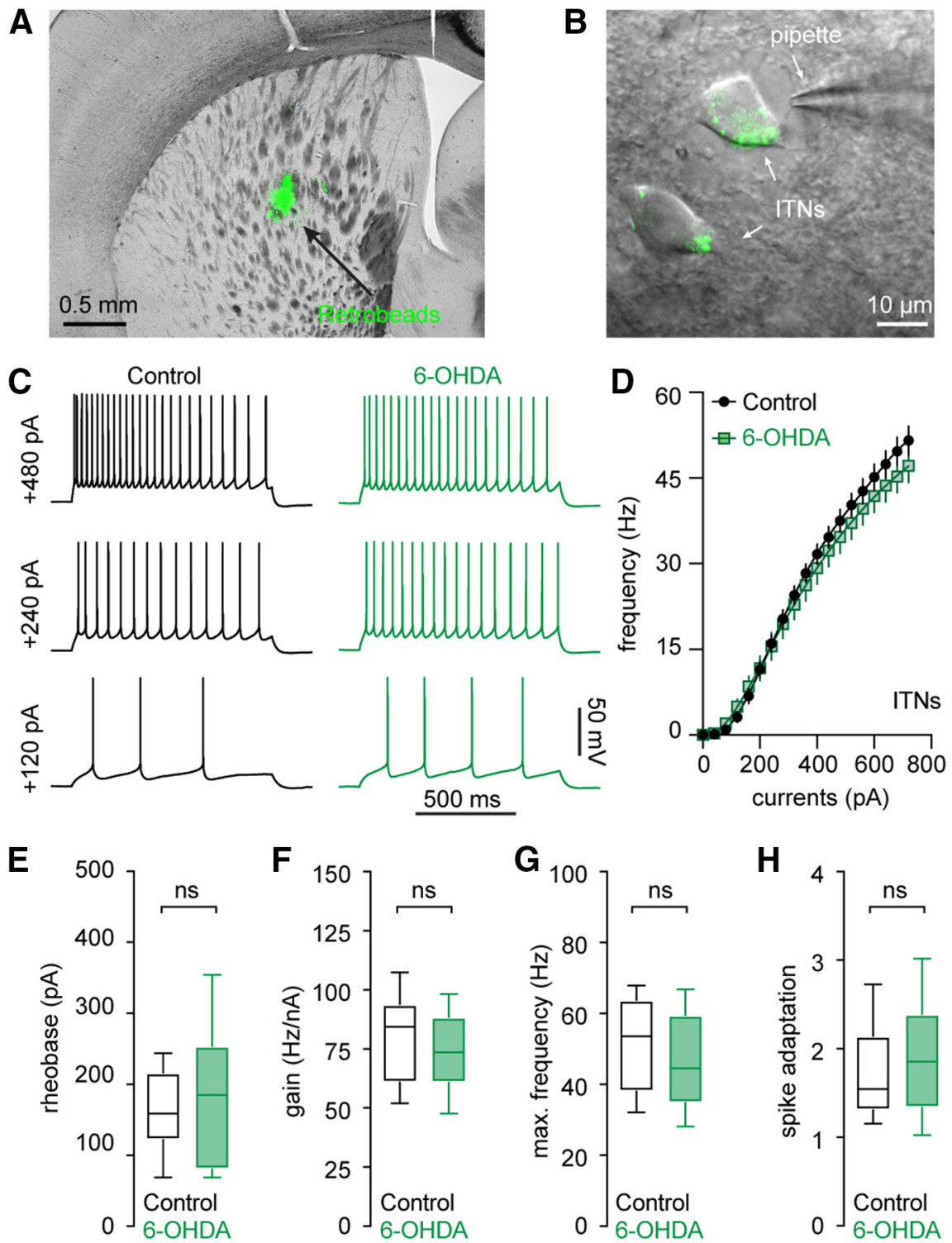

Figure 2. Intact intrinsic excitability of ITNs in the M1 L5b following the loss of midbrain DA neurons. $\boldsymbol{A}, \boldsymbol{B}$ Representative graphs showing the injection site of green Retrobeads in the dorsal striatum $(\boldsymbol{A})$ and retrogradely labeled $M 1$ (B). C, D, Representative spikes trains evoked by somatic current injections into ITNs from controls and 6-OHDA an $(\boldsymbol{E})$, an unaltered gain of spike-current curve $(\boldsymbol{F})$, firing frequency in response to maximal current injections (i.e., $720 \mathrm{pA} ; \boldsymbol{G})$, and spike adaptation $(\boldsymbol{H})$ between ITNs from 6-0HDA mice and controls. ns, not significant, MWU.

The intrinsic excitability of M1 pyramidal neuron subtypes was assessed by somatic injection of a range of depolarizing currents from $\mathrm{V}_{\mathrm{m}}$ in controls and 6-OHDA mice (Fig. 1C,D). First, the intensity of somatic current injection to elicit single AP increased significantly for PTNs from 6-OHDA mice relative to controls (rheobase, control $=126[80,220] \mathrm{pA}), n=39$ neurons $/ 4$ mice, $6-\mathrm{OHDA}=175[120,250] \mathrm{pA}, n=30$ neurons $/ 3$ mice, $p=0.03$, MWU; Fig. 1E). Moreover, the gain of spike-current curve decreased significantly in M1 PTNs from 6-OHDA mice relative to controls (control $=97[95,98] \mathrm{Hz} / \mathrm{nA}, n=39$ neurons/ 4 mice; 6-OHDA $=62[44,73] \mathrm{Hz} / \mathrm{nA}, n=30$ neurons $/ 3$ mice; $p<0.0001$, MWU; Fig. $1 F)$. The same reduction was also detected for the maximal spike frequency (e.g., frequency at 720 pA current injection, control $=47[39,57] \mathrm{Hz}, n=39$ neurons $/ 4$ mice; $6-\mathrm{OHDA}=38 \quad[23,45] \mathrm{Hz}, n=30$ neurons $/ 3$ mice; $p=0.0002$, MWU; Fig. 1G). M1 PTNs could sustain persistent 

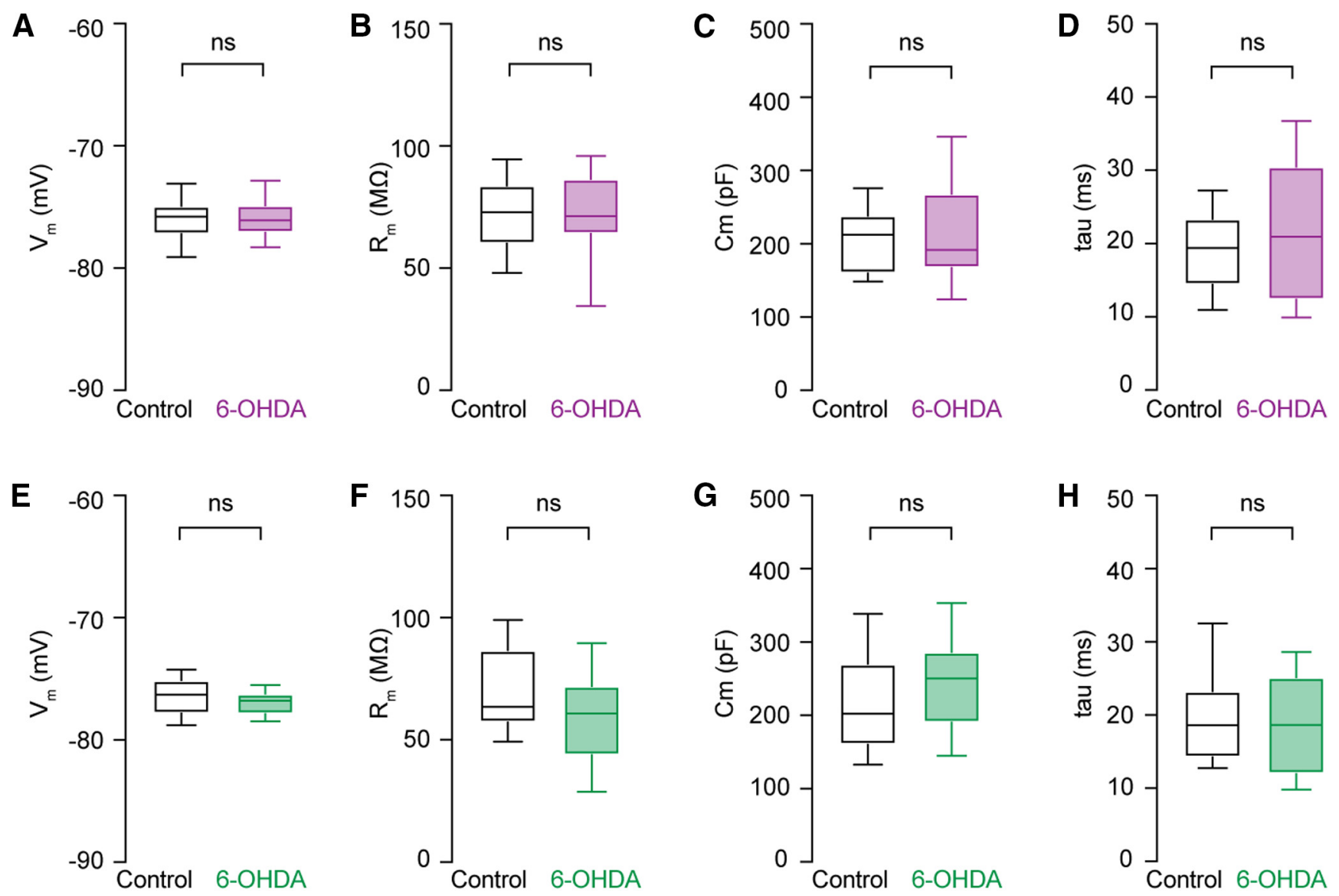

Figure 3. No change in the passive membrane properties of PTNs and ITNs in the M1 L5b following the loss of midbrain DA neurons. $A-D$, Boxplots showing no changes in the resting membrane potential $(\boldsymbol{A})$, input resistance $(\boldsymbol{B})$, cell capacitance $(\boldsymbol{C})$, and time constant $(\boldsymbol{D})$ of PTNs from $6-0 \mathrm{HDA}$ mice relative to those from controls. $\boldsymbol{E}-\boldsymbol{H}$, Similar measures on passive membrane properties of ITNs from controls and 6-OHDA mice. ns, not significant, MWU.

firing with minimal spike adaptation during repetitive firing in the physiological state (Fig. 1C; Oswald et al., 2013; Suter et al., 2013). However, PTNs showed significantly enhanced spike adaptation in 6-OHDA mice (Fig. 1C). The spike adaptation of a $10-\mathrm{Hz}$ spike train, control $=1.2[1.0,1.6], n=39$ neurons $/ 4$ mice; $6-O H D A=1.6$ $[1.3,2.3], n=30$ neurons/3 mice; $p=0.0011$, MWU (Fig. $1 C, H$ ). Altogether, these results suggest a significant reduction in the intrinsic excitability of M1 PTNs in parkinsonism.

In contrast, M1 ITNs from controls and 6-OHDA mice showed comparable intrinsic excitability (Fig. 2). This was reflected by four measures, namely, (1) similar rheobase (control $=155[118,213] \mathrm{pA}, 6-\mathrm{OHDA}=184[79,252] \mathrm{pA}, n=30$ neurons/ 3 mice for each group, $p=0.4$, MWU; Fig. $2 E$ ); (2) the unaltered gain of spike-current curve (control $=84[61,94] \mathrm{Hz}$ / $\mathrm{nA}, 6-\mathrm{OHDA}=74[61,89] \mathrm{Hz} / \mathrm{nA}, n=30$ neurons $/ 3$ mice for each group; $p=0.3$, MWU; Fig. $2 F$ ); (3) the maximal spike frequency (control $=53[38,64] \mathrm{Hz}, 6-\mathrm{OHDA}=45[35,60] \mathrm{Hz}$, $n=30$ neurons $/ 3$ mice for each group; $p=0.15$, MWU; Fig. $2 D$, $G$ ); and (4) spike adaptations (control = $1.6[1.3,2.2]$, 6$\mathrm{OHDA}=1.9[1.3,2.4], n=30$ neurons $/ 3$ mice for each group; $p=0.39$, MWU; Fig. 2C,H). Altogether, our results thus suggest that the M1 L5b pyramidal neurons exhibited cell type-specific decrease of intrinsic excitability in parkinsonism.

No change in the passive membrane properties of M1 L5b pyramidal neurons following the loss of midbrain DA neurons Next, we determined whether alterations in the passive membrane properties contribute to the difference in the intrinsic excitability of M1 PTNs and ITNs in parkinsonism. In the presence of antagonists of fast ionotropic glutamatergic and GABAergic receptors, PTNs in 6-OHDA mice and controls had similar resting membrane potential $\left(\mathrm{V}_{\mathrm{m}}\right.$, control $=-75.8$ $[-77.2,-74.9] \mathrm{mV}, n=39$ neurons/4 mice; 6-OHDA $=-76.1$ $[-77.1,-74.9] \mathrm{mV}, n=30$ neurons/3 mice; $p=0.87$, MWU; Fig. $3 A)$ and input resistance $\left(\mathrm{R}_{\mathrm{m}}\right.$, control $=72.9[60,83.8] \mathrm{M} \Omega$, $n=39$ neurons/4 mice; 6-OHDA = $71.3[64,86.6] \mathrm{M} \Omega, n=30$ neurons $/ 3$ mice; $p=0.91$, MWU; Fig. $3 B$ ). In addition, PTNs from 6-OHDA mice did not show changes in their cell capacitance $\left(\mathrm{C}_{\mathrm{m}}\right)$ and membrane time constant $\left(\tau_{\mathrm{m}}\right)$ relative to those from controls $\left[\mathrm{C}_{\mathrm{m}}\right.$, control $=212[160,239] \mathrm{pF}, n=39$ neurons $/ 4$ mice, 6-OHDA $=192[167,268] \mathrm{pF}, n=30$ neurons $/ 3$ mice, $p=0.7$, MWU (Fig. 3C); $\tau_{\mathrm{m}}$, control $=19.4[14.4,23.4] \mathrm{ms}, n=39$ neurons $/ 4$ mice, 6-OHDA = $20.9[12.4,30.5] \mathrm{ms}, n=30$ neurons/ 3 mice, $p=0.5$, MWU (Fig. $3 D$ )].

Similarly, ITNs showed comparable passive membrane properties between groups, namely, $\mathrm{V}_{\mathrm{m}}$ (control $=-76.3[-77.8$, -75.1] $\mathrm{mV}, 6-\mathrm{OHDA}=-76.8[-77.9,-76.2] \mathrm{mV}, n=30$ neurons/3 mice for each group, $p=0.2$, MWU; Fig. $3 E), \mathrm{R}_{\mathrm{m}}$ (control =63.5 $[57.1,86.7] \mathrm{M} \Omega, 6-\mathrm{OHDA}=60.8[43.8,72] \mathrm{M} \Omega$, $n=30$ neurons $/ 3$ mice for each group, $p=0.15$, MWU; Fig. $3 F$ ), $\mathrm{C}_{\mathrm{m}}($ control $=202[160,270] \mathrm{pF}, 6-\mathrm{OHDA}=250[190,287] \mathrm{pF}$, $n=30$ neurons $/ 3$ mice for each group, $p=0.13$, MWU; Fig. $3 G$ ), and $\tau_{\mathrm{m}}$ (control $=18.6[14.2,23.3] \mathrm{ms}, 6-\mathrm{OHDA}=18.6[12,25.2]$ $\mathrm{ms}, n=30$ neurons $/ 3$ mice for each group, $p=0.6$, MWU; Fig. $3 H)$. Altogether, these results suggest that the cell type-specific decrease in the excitability of M1 pyramidal neurons is not because of alterations in their passive membrane properties. 

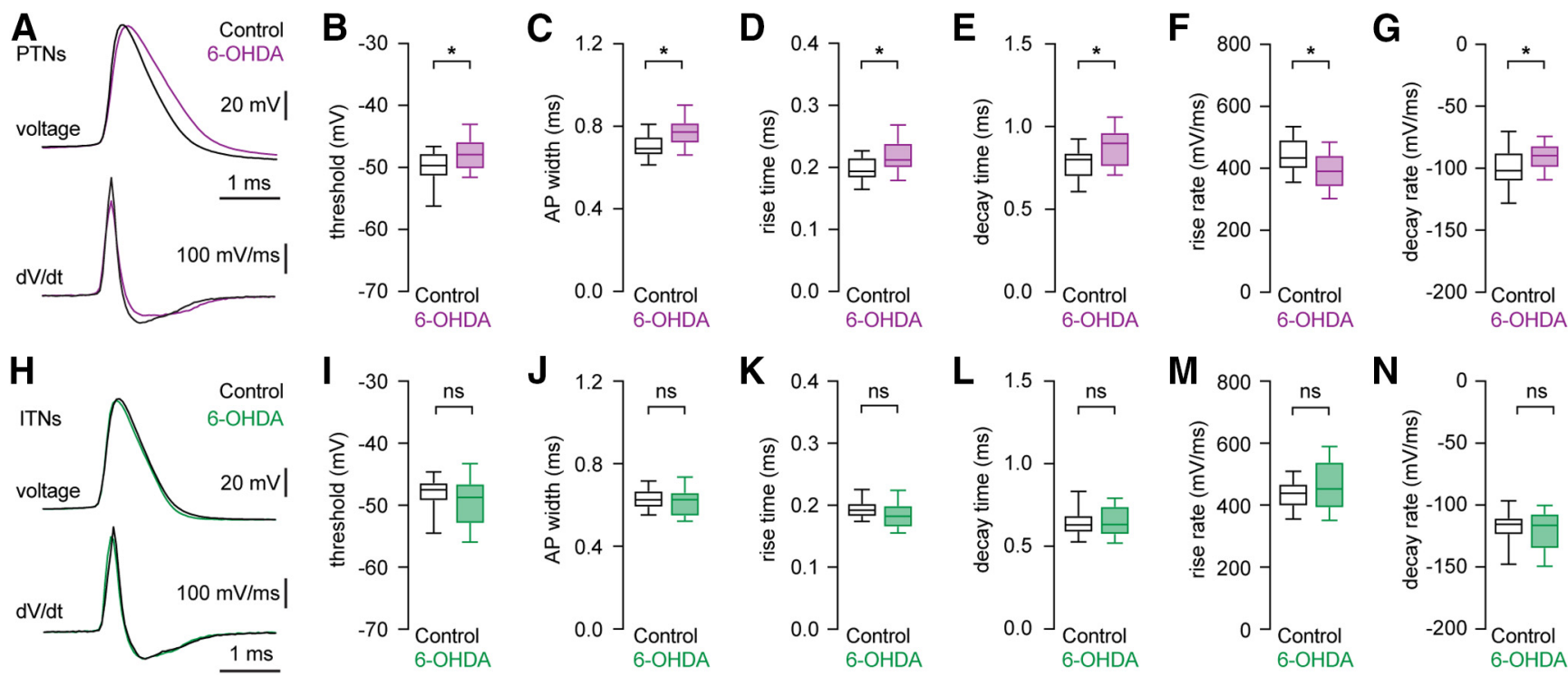

Figure 4. Distinct changes in AP waveforms of PTNs and ITNs in the M1 L5b following loss of midbrain DA neurons. $A$, top, Representative AP waveforms of PTNs from controls and 6-OHDA mice. APs were aligned at threshold and overlaid for comparison. Bottom, Corresponding $d V / d t$ traces plotted against time, showing depolarizing and repolarizing rates of APs. $B, C$, Boxplots showing AP threshold and width of PTNs in 6-OHDA mice and controls. $\boldsymbol{D}, \boldsymbol{E}$, Boxplots showing prolonged AP rise time $(\boldsymbol{D})$ and decay time $(\boldsymbol{E})$ in PTNs from 6-0HDA mice relative to those from controls. $\boldsymbol{F}, \mathbf{G}$, Boxplots showing decreased AP rise rate $(\boldsymbol{F})$ and decay rate $(\boldsymbol{G})$ in PTNs from 6-OHDA mice relative to those from controls. $\boldsymbol{H}$, top, Representative AP waveforms of ITNs from controls and 6-OHDA mice. APs were aligned at threshold and overlaid for comparison. Bottom, Corresponding $d V / d t$ traces plotted against time, showing depolarizing and repolarizing rates of APs. $\boldsymbol{I}-\boldsymbol{N}$, Boxplot showing similar AP threshold $(\boldsymbol{I})$ and width $(\boldsymbol{J})$, rise $(\boldsymbol{K})$, and decay $(\boldsymbol{L})$ time, as well as rise $(\boldsymbol{M})$ and decay $(\boldsymbol{N})$ rates in ITNs from 6-0HDA mice relative to those from controls. ns, not significant; ${ }^{*} p<0.05$, MWU.

\section{Cell type-specific changes in AP waveforms of M1 L5b pyramidal neurons following the loss of midbrain DA neurons}

The shape of the AP is determined by the interaction of numerous voltage-gated ion channels and has profound effects on the rate and pattern of neuronal firing (Bean, 2007). We therefore analyzed the morphology of AP of PTNs and ITNs at the rheobase from controls and 6-OHDA mice (Fig. 4A,H). In parkinsonian animals, M1 PTNs showed a depolarized AP threshold (controls $=-49.7[-51.5,-47.7] \mathrm{mV}, n=39$ neurons $/ 4$ mice, 6 OHDA $=-47.9[-50.3,-45.8] \mathrm{mV}, n=30$ neurons $/ 3$ mice, $p=0.015$, MWU; Fig. $4 B$ ) and a striking AP broadening (AP half-width, controls $=0.69[0.66,0.75] \mathrm{ms}, n=39$ neurons $/ 4$ mice; $6-\mathrm{OHDA}=0.77[0.72,0.82] \mathrm{ms}, n=30$ neurons $/ 3$ mice; $p=0.0008$, MWU; Fig. $4 C$ ). The broadened AP of PTNs was associated with a significantly prolonged AP rise time (controls $=0.19[0.18,0.22] \mathrm{ms}, n=39$ neurons $/ 4$ mice; 6$\mathrm{OHDA}=0.21[0.2,0.24] \mathrm{ms}, n=30$ neurons $/ 3$ mice; $p=0.0024$, MWU; Fig. $4 D$ ) and also a prolonged decay time (controls $=0.8$ $[0.69,0.84] \mathrm{ms}, n=39$ neurons/4 mice, 6-OHDA $=0.9[0.76$, $0.97] \mathrm{ms}, 30$ neurons/ 3 mice; $p=0.0023$, MWU; Fig. $4 E$ ). In parkinsonian animals, M1 PTNs also exhibited significant decreases in the maximal rates of $\mathrm{AP}$ depolarization (the rise rate, controls $=434[398,493] \mathrm{mV} / \mathrm{ms}, n=39$ neurons $/ 4$ mice, 6$\mathrm{OHDA}=390[340,443] \mathrm{mV} / \mathrm{ms}, \quad n=30$ neurons $/ 3$ mice, $p=0.004$, MWU; Fig. $4 F$ ) and repolarization (the decay rate, controls $=-102[-87,-111] \mathrm{mV} / \mathrm{ms}, n=39$ neurons $/ 4$ mice, and $6-\mathrm{OHDA}=-90[-81,-99] \mathrm{mV} / \mathrm{ms}, n=30$ neurons $/ 3$ mice, $p=0.012$, MWU; Fig. 4G). Thus, the decreased excitability of PTNs in parkinsonism involves impairments in both $\mathrm{Na}^{+}$and $\mathrm{K}^{+}$conductance that underlies AP depolarization and repolarization, respectively (Bean, 2007).

In contrast, ITNs from controls and 6-OHDA mice showed unaltered AP threshold (controls $=-47.5[-49.3$, -46.3] $\mathrm{mV}, 6$-OHDA $=-48.7[-53,-46.5] \mathrm{mV}, n=30$ neurons/3 mice for each group, $p=0.24$, MWU; Fig. $4 I$ ) and AP width (controls $=0.63[0.59,0.67] \mathrm{ms} ; 6-\mathrm{OHDA}=0.63$ $[0.55,0.66] \mathrm{ms}, n=30$ neurons $/ 3$ mice for each group; $p=0.56$, MWU; Fig. 4J). The similar AP width of ITNs was associated with unaltered time and rates of AP depolarization and repolarization. The rise time was controls $=0.19$ $[0.18,0.2] \mathrm{ms}$, and 6-OHDA $=0.18[0.16,0.2] \mathrm{ms} \quad(p=0.13$, MWU; Fig. $4 K)$. The decay time was controls $=0.63[0.58$, $0.69] \mathrm{ms}$, and 6-OHDA $=0.63[0.57,0.074] \mathrm{ms}(p=0.94$, MWU; Fig. 4L). The rise rate values were, controls $=438$ $[396,469] \mathrm{mV} / \mathrm{ms}$, and 6-OHDA $=452[390,541] \mathrm{mV} / \mathrm{ms}$ $(p=0.3$, MWU; Fig. $4 M)$, and the decay rate values were, controls $=-115[-110,-124] \mathrm{mV} / \mathrm{ms}$, and 6-OHDA = $-116[-107,-135] \mathrm{mV} / \mathrm{ms}(p=0.67$, MWU; Fig. $4 N)$.

Altogether, these results suggest that disrupted ionic mechanisms for AP generation contribute to cell type-specific decrease in the intrinsic excitability of PTNs in parkinsonism.

\section{Progressive alterations in AP waveforms of PTNs during repetitive firing following the loss of SN DA neurons}

The literature suggests that M1 PTNs are capable to sustain constant AP waveform during repetitive firing (Suter et al., 2013). Thus, we elicited spike trains containing 10 APs from M1 PTNs in controls and 6-OHDA mice and analyzed waveforms of the first and the last APs to study activity-dependent AP modulation during repetitive firing. We noticed a stronger activity-dependent AP waveform modulation in PTNs from 6-OHDA mice relative to those from controls (Fig. 5A,B). Specifically, PTNs from both groups exhibited an increased AP threshold during repetitive firing (threshold in controls, first $\mathrm{AP}=-51.8[-54.8,-50.5]$ $\mathrm{mV}$, last $\mathrm{AP}=-50.7[-52.7,-47.8] \mathrm{mV}, n=25$ neurons $/ 5$ mice, $p<0.001$, WSR; threshold in 6-OHDA mice, first AP $=-51$ $[-52.5,-47.1] \mathrm{mV}$, last $\mathrm{AP}=-47.2[-48.8,-45.6] \mathrm{mV}, n=25$ neurons/5 mice, $p<0.001$, WSR; Fig. $5 C$ ). Repetitive firing leads to a significantly depolarized threshold of the last APs from 6- 

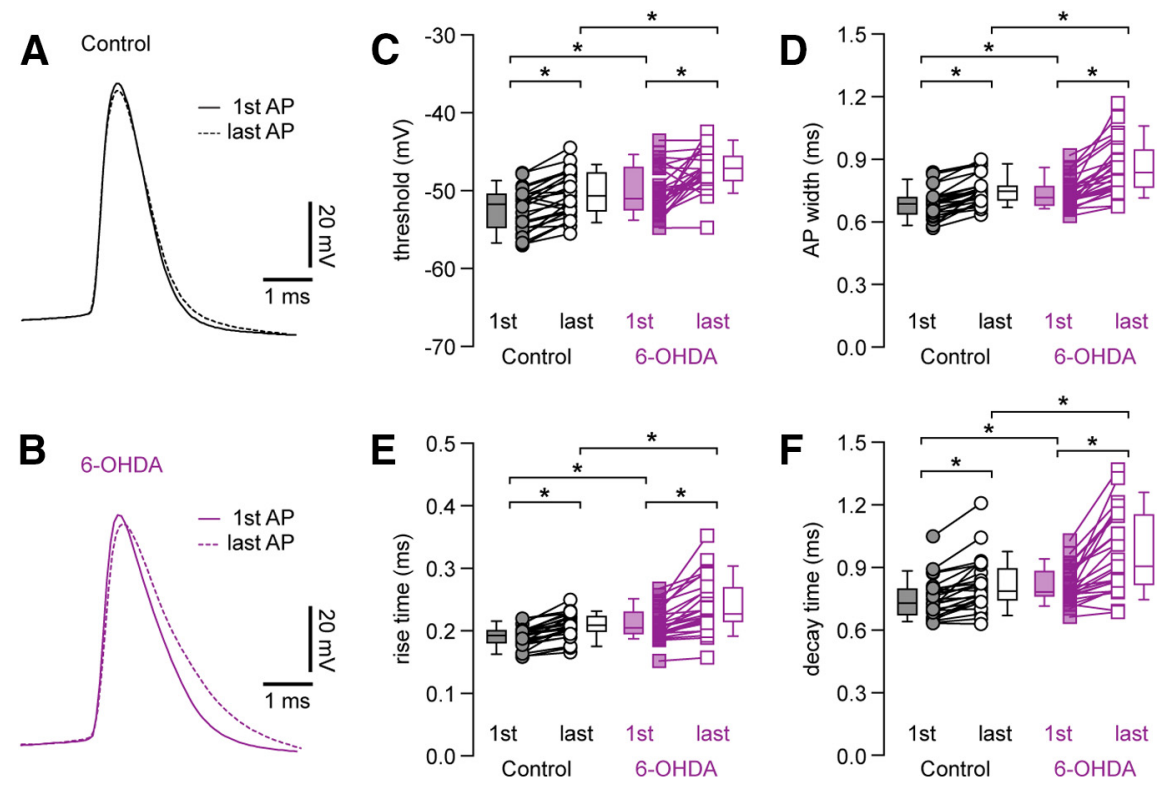

Figure 5. Progressive changes in AP waveforms of M1 PTNs during repetitive firing. $\boldsymbol{A}, \boldsymbol{B}$, The first and the tenth APs from a $10-\mathrm{Hz}$ spike train were superimposed for PTNs from control $(\boldsymbol{A})$ or 6-0HDA mice $(\boldsymbol{B})$. APs were aligned at threshold, and the solid and dashed lines indicated the first and the last APs from the spike train, respectively. $C$, Summarized graphs showing the alterations of AP threshold between the first and the last APs. Each line connects the AP width of the first and the last APs from the same spike train. Box plots indicate the median plus interquartile range of the first and the last AP. D-F, Summarized graphs showing changes in AP width $(\boldsymbol{D})$, rise time $(\boldsymbol{E})$, and decay time $(\boldsymbol{F})$ between the first and the last APs in PTNs from 6-OHDA mice relative to those from controls; ${ }^{*} p<0.05$, WSR or MWU tests.

OHDA mice relative to those from controls $(p=0.0003$ between groups, MWU; Fig. $5 C$ ), in addition to the elevated threshold of the first APs ( $p=0.02$ between groups, MWU; Fig. $5 C)$. This is consistent with activity-dependent inactivation of voltage-dependent transient $\mathrm{Na}^{+}$channels $\left(\mathrm{Na}_{\mathrm{T}}\right)$ during sustained firing (Bean, 2007).

APs of PTNs in both controls and 6-OHDA mice also progressively broadened during repetitive firing (AP width in controls, first $\mathrm{AP}=0.68[0.64,0.72] \mathrm{ms}$, last $\mathrm{AP}=0.75[0.7,0.77] \mathrm{ms}$, $n=25$ neurons $/ 5$ mice, $p<0.0001$, WSR; AP width in 6-OHDA mice, first $\mathrm{AP}=0.72[0.68,0.77] \mathrm{ms}$, last $\mathrm{AP}=0.84[0.76,0.94]$ ms, $n=25$ neurons/5 mice, $p<0.0001$, WSR; Fig. 5D). Importantly, repetitive firing led to a significantly broadened last APs in 6-OHDA mice relative to controls (width of the last AP, $p=0.0004$ between groups, MWU; Fig. 5D), in addition to the broadened first AP (width of the first AP, $p=0.01$ between groups, MWU; Fig. 5D). Moreover, the observed activity-dependent modulation of AP waveforms associated with prolonged rise and decay time in controls and 6-OHDA mice (Fig. 5E,F). The values of AP rise time in controls were, the first $\mathrm{AP}=0.19$ $[0.18,0.2] \mathrm{ms}$, the last $\mathrm{AP}=0.21[0.2,0.22] \mathrm{ms}(n=25$ neurons $/ 5$ mice, $p<0.0001$, WSR; Fig. $5 E$ ) and the values for AP rise time in 6-OHDA mice were, the first $\mathrm{AP}=0.2[0.19,0.23] \mathrm{ms}$, the last $\mathrm{AP}=0.23[0.21,0.27] \mathrm{ms}(n=25$ neurons $/ 5$ mice, $p<0.0001$, WSR; Fig. $5 E)$. The rise time of the first APs $(p=0.005$ between groups, MWU; Fig. $5 F)$ and last APs ( $p=0.004$ between groups, MWU; Fig. $5 F$ ) were both significantly increased in 6-OHDA mice relative to those in controls. Similarly, the values of AP decay time in controls were, the first $\mathrm{AP}=0.73[0.67,0.8] \mathrm{ms}$, the last $\mathrm{AP}=0.79[0.74,0.89] \mathrm{ms}(n=25$ neurons $/ 5$ mice, $p<0.0001$, WSR; Fig. $5 F$ ). And the values AP decay time in 6-OHDA were, the first $\mathrm{AP}=0.78[0.76,0.88] \mathrm{ms}$, the last $\mathrm{AP}=0.91[0.82,1.15]$ $\mathrm{ms}(n=25$ neurons/5 mice, $p<0.0001$, WSR; Fig. $5 F)$. The decay time of the first APs ( $p=0.01$ between groups, MWU; Fig. $5 F)$ and the last APs ( $p=0.002$, MWU; Fig. $5 F$ ) were both significantly increased in 6OHDA mice relative to those in controls.

Altogether, these results suggest that PTNs in parkinsonism show a stronger activity-dependent AP modulation, which, at least partially, leads to a decreased intrinsic excitability.

\section{Impaired function of persistent $\mathrm{Na}^{+}$ currents contributes to the increased threshold and decreased intrinsic excitability of PTNs in parkinsonism} Persistent sodium current $\left(I_{\text {Nap }}\right)$ plays an important role in determining AP threshold and its dysfunction contributes to disrupted neuronal activity in several neurologic diseases (Bean, 2007; Milescu et al., 2010; Deng and Klyachko, 2016). Given the altered AP threshold and rising phase of APs in 6-OHDA mice (Fig. $4 B, D, F$ ), we next examined whether $I_{\mathrm{Nap}}$ contributes to these alterations. Blockade of $I_{\mathrm{Nap}}$ by bath application of low concentration of tetrodotoxin (TTX; $20 \mathrm{~nm}$ ) significantly elevated the AP threshold at rheobase of PTNs from controls and 6-OHDA mice (controls, baseline $=-50.8[-53.7,-50]$ $\mathrm{mV}$, TTX $=-41.1[-42.3,-38.2] \mathrm{mV}$, $n=11$ neurons $/ 3$ mice, $p=0.001$, WSR; 6-

OHDA, baseline $=-48.8[-49.4,-46.5] \mathrm{mV}$, TTX $=-41.2$ $[-43.5,-39.4] \mathrm{mV} ; n=13$ neurons $/ 4$ mice, $p=0.0002$, WSR; Fig. $6 A-C)$. TTX $(20 \mathrm{~nm})$ also abolished the difference in AP threshold between groups (AP threshold, before TTX, $p=0.0018$; in TTX, $p=0.5$, MWU; Fig. $6 C$ ). In contrast, blockade of $I_{\mathrm{Nap}}$ did not affect AP width at rheobase of PTNs either in controls (baseline $=0.68[0.61,0.72] \mathrm{ms}, \mathrm{TTX}=0.7[0.62,0.82] \mathrm{ms}$, $p=0.2$, WSR; Fig. $6 D$ ) or in 6-OHDA mice (baseline $=0.8[0.7$, $0.81] \mathrm{ms}$, TTX $=0.77[0.7,0.83] \mathrm{ms}, p=0.9$, WSR; Fig. $6 D)$. With the blockade of $I_{\text {Nap }}$, PTNs from controls and 6-OHDA mice also exhibited activity-dependent increase in AP threshold during repetitive firing of 10 APs (controls in TTX, first AP $=-47.1$ $[-49.5,-40.7] \mathrm{mV}$, last $\mathrm{AP}=-40.9[-45.8,-38.6] \mathrm{mV}$, $p=0.004$, WSR, $n=9$ neurons $/ 3$ mice; $6-O H D A$ in TTX, first AP $=-46.3[-51.7,-43.1] \mathrm{mV}$, last $\mathrm{AP}=-41.4[-44.8,-35.8]$ $\mathrm{mV}, p=0.0005$, WSR, $n=13$ neurons/4 mice; Fig. $6 E)$. Further, TTX also abolished the difference in AP threshold of both the first and the last APs during repetitive firing (threshold of the first AP, $p=0.65$ between groups; threshold of the last AP, $p=0.7$ between groups, MWU; Fig. 6E). These results indicate that disrupted $I_{\text {Nap }}$ function underlies the elevated AP threshold in 6OHDA mice.

Next, we tested the hypothesis that a decreased basal $I_{\text {Nap }}$ activity exacerbates activity-dependent $\mathrm{Na}_{\mathrm{T}}$ inactivation and leads to a decreased excitability of PTNs in 6-OHDA mice. As expected, blockade of $I_{\text {Nap }}$ by TTX $(20 \mathrm{~nm})$ significantly decreased the number of APs of PTNs from controls and 6OHDA mice (Fig. 6F,G). For example, the maximal number of APs in controls were, baseline $=48[40,56]$, TTX $=26[16,34]$ ( $n=11$ neurons $/ 3$ mice, $p=0.001$, WSR; Fig. $6 H$ ) and in 6OHDA mice were, baseline $=44[37,49]$, TTX $=24[10,37]$ ( $n=13$ neurons/4 mice, $p=0.002$, WSR; Fig. $6 H$ ). Importantly, TTX abolished the difference in intrinsic excitability of PTN 

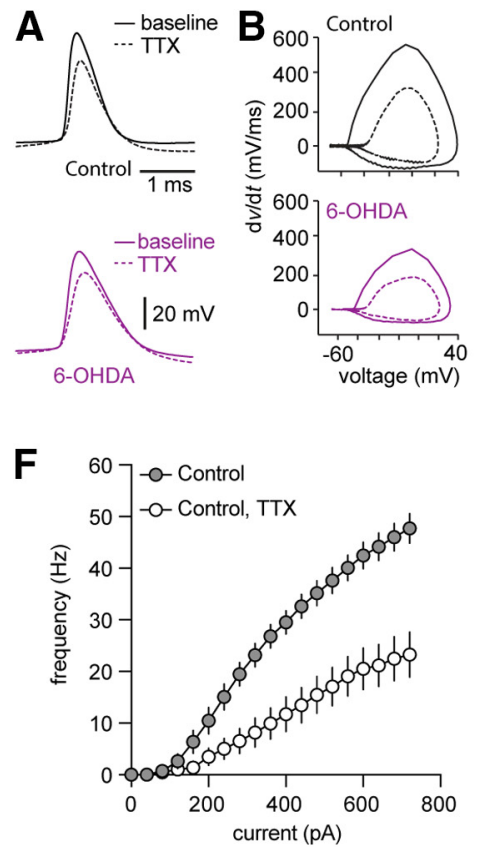
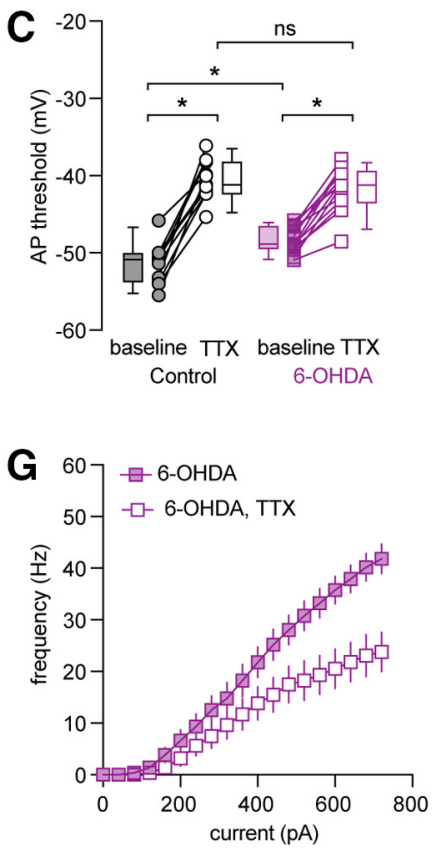
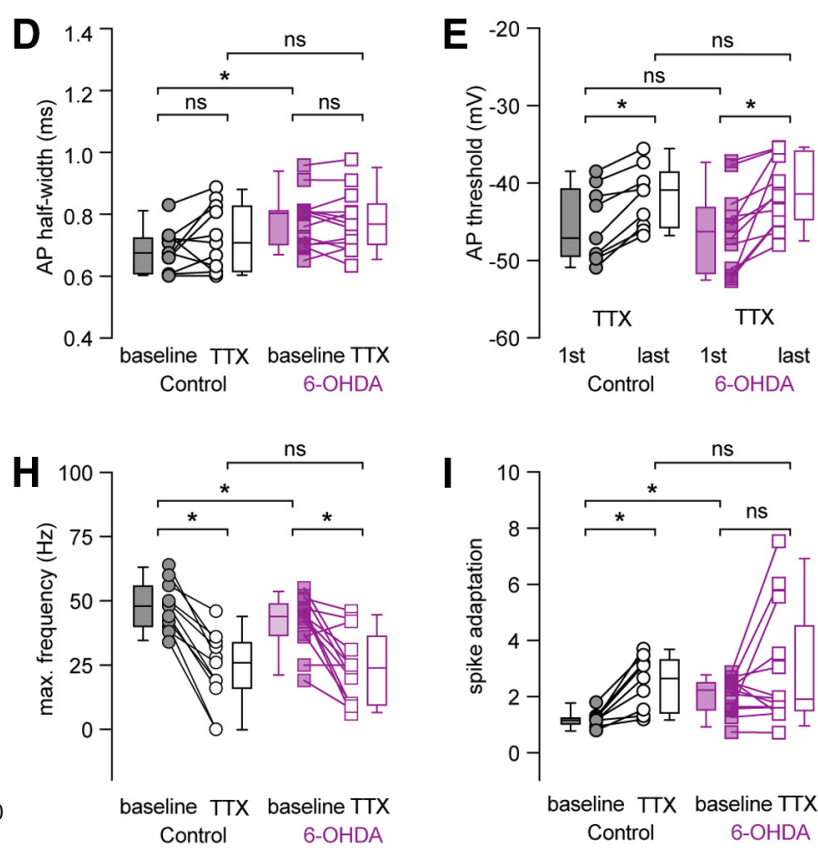

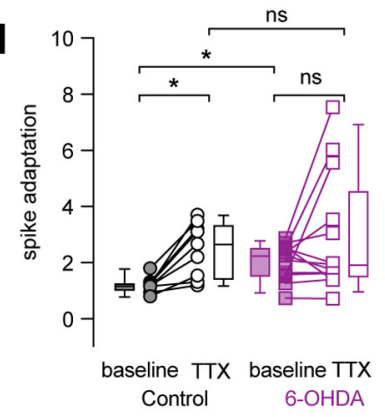

Figure 6. Low-concentration TTX excludes the decreased intrinsic excitability of PTNs in 6-OHDA mice versus controls. $\boldsymbol{A}, \boldsymbol{B}$, Representative AP waveforms of PTNs at rheobase from controls $(\boldsymbol{A}$, up) and 6-OHDA mice $(\boldsymbol{A}$, bottom) and the corresponding phase plane plots at baseline and in the presence of TTX (20 nM). $\boldsymbol{C}, \boldsymbol{D}$, Summarized graphs showing changes in AP threshold $(\boldsymbol{C})$ and half-width $(\boldsymbol{D})$ at rheobase in the absence and presence of TTX (20 nM). $\boldsymbol{E}$, Summarized graph showing threshold changes of PTNs from controls and 6-0HDA mice during repetitive firing of 10 APs in the presence of TTX (20 nM). $\boldsymbol{F}, \mathbf{G}$, Current-frequency curves of PTNs from controls and 6-OHDA mice in the absence and presence of TTX (20 nM). $\boldsymbol{H}, \boldsymbol{I}$, summarized graphs showing changes in the maximal firing frequency $(\boldsymbol{H})$ and spike adaptation $(\boldsymbol{I})$ of PTNs from controls and 6-0HDA mice in the absence and presence of TTX (20 nM); ${ }^{*} p<0.05$, n.S., not significant. WSR or MWU tests.

between groups (AP numbers in TTX between groups, $p=0.96$, MWU; Fig. $6 H)$.

It has been reported that $\mathrm{Na}_{\mathrm{T}}$ inactivation contribute to spike adaptation during repetitive firing (Fleidervish et al., 1996; Milescu et al., 2010). Consistently, blockade of $I_{\text {Nap }}$ by TTX (20 nM), which promotes $\mathrm{Na}_{\mathrm{T}}$ inactivation, dramatically increased spike adaptation in PTNs from controls (adaptation index, baseline $=1.18[1.0,1.2]$, TTX $=2.67[1.43,3.34], n=9$ neurons $/ 3$ mice, $p=0.0039$, WSR; Fig. $6 I$ ), but had little effect to those from 6-OHDA mice (adaptation index, baseline $=2.26[1.55,2.53]$, TTX $=1.93[1.51,4.55], n=13$ neurons $/ 4$ mice, $p=0.34$, WSR; Fig. 6I). Furthermore, TTX abolished the difference in spike adaptation between groups (controls vs 6-OHDA mice at baseline, $p=0.002$; in TTX, $p=1$, MWU; Fig. $6 I$ ).

Thus, these data indicated that $I_{\mathrm{Nap}}$ dysfunction reduces the availability of $\mathrm{Na}_{\mathrm{T}}$ for AP generation and exacerbates their inactivation during repetitive firing, leading to a decreased intrinsic excitability of PTNs in parkinsonism.

\section{Impaired activity of $\mathrm{BK}$ channels underlies the broadened} APs of M1 PTNs following the loss of midbrain DA neurons We further examined the ionic mechanisms underlying broadened APs of PTNs in 6-OHDA mice. Following the loss of midbrain DA neurons, the amplitude of the fAHP in PTNs decreased significantly (controls $=12.5[10.5,14.3] \mathrm{mV}, n=39$ neurons/4 mice; 6-OHDA $=11.2[10.5,11.9] \mathrm{mV}, n=30$ neurons $/ 3$ mice; $p=0.036, \mathrm{MWU})$. These observations suggest that an altered BK channel activity probably underlies the broadened AP of PTNs in 6-OHDA mice, considering its role in AP repolarization, fAHPs, and AP broadening during neuronal repetitive firing in other brain regions (Faber and Sah, 2003; Bean, 2007; Contet et al., 2016).

Consistently, the difference in AP width at rheobase of PTNs between groups was abolished by intracellular BAPTA (10 mM, a high-affinity $\mathrm{Ca}^{2+}$ chelator; controls $=0.84[0.79,0.92] \mathrm{ms}, n=26$ neurons $/ 3$ mice; $6-O H D A=0.86[0.78,0.94] \mathrm{ms}, n=26$ neurons $/ 3$ mice, $p=0.84$, MWU; Fig. $7 A, B)$. Moreover, in the presence of intracellular BAPTA, PTNs neurons still show activity-dependent AP broadening in both controls (first $\mathrm{AP}=0.78[0.68,0.86] \mathrm{ms}$, last $\mathrm{AP}=1.14[0.97,1.24] \mathrm{ms}, n=17$ neurons $/ 3$ mice, $p<0.0001$, WSR; Fig. 7C) and 6-OHDA mice (first $\mathrm{AP}=0.78[0.73,0.87] \mathrm{ms}$, last $\mathrm{AP}=1.14[0.94,1.33] \mathrm{ms}, n=16$ neurons $/ 3$ mice, $p<0.0001$, WSR; Fig. 7C). However, the extent of AP broadening during repetitive firing (10 spikes) was comparable between groups (controls vs 6-OHDA mice, half-width of the first AP, $p=0.5$ between groups; half-width of the last AP, $p=0.8$ between groups, MWU). Further, the PTNs from both groups also showed similar intrinsic excitability in the presence of BAPTA (Fig. 7D). For example, the number of spikes at the maximal current injection for controls $=38[21,55]$, while the value for $6-\mathrm{OHDA}=29[18,40]$, $n=26$ neurons $/ 3$ mice for each group; $p=0.29$, MWU test.

Next, we inhibited BK channel activity by a selective blocker paxillin $(10 \mu \mathrm{M})$ and found that paxillin significantly decreased fAHP amplitude of PTNs in controls (baseline $=11.2[7.7,12.6]$ $\mathrm{mV}$; paxillin $=8.3[3.5,10] \mathrm{mV}, n=12$ neurons $/ 3$ mice, $p=0.005$, WSR), but not in 6-OHDA mice (baseline $=8.7[7.3,9.0] \mathrm{mV}$; paxillin $=8.7 \quad[5.9,9.8] \mathrm{mV}, n=12$ neurons $/ 3$ mice, WSR). Consistently paxillin significantly increased AP half-width of PTNs at rheobase in controls (baseline $=0.7[0.66,0.79] \mathrm{ms}$, paxillin $=0.83[0.78,0.91] \mathrm{ms}, n=12$ neurons $/ 3$ mice, $p=0.0024$, WSR; Fig. 7E,G), but not in 6-OHDA mice (baseline $=0.85[0.8$, $0.97] \mathrm{ms}$, paxillin $=0.88[0.83,0.95] \mathrm{ms}, n=12$ neurons $/ 3$ mice, $p=0.27$, WSR; Fig. $7 F, G$ ). Thus, blockade of BK channels by paxillin abolished the difference in AP half-width of PTNs at rheobase in control and 6-OHDA mice (AP half-width in paxillin, $p=0.22$ between groups, MWU; Fig. 7G). These results suggests that $\mathrm{BK}$ channel activation contributes to AP repolarization and width of PTNs in controls, but not in 6-OHDA mice. 

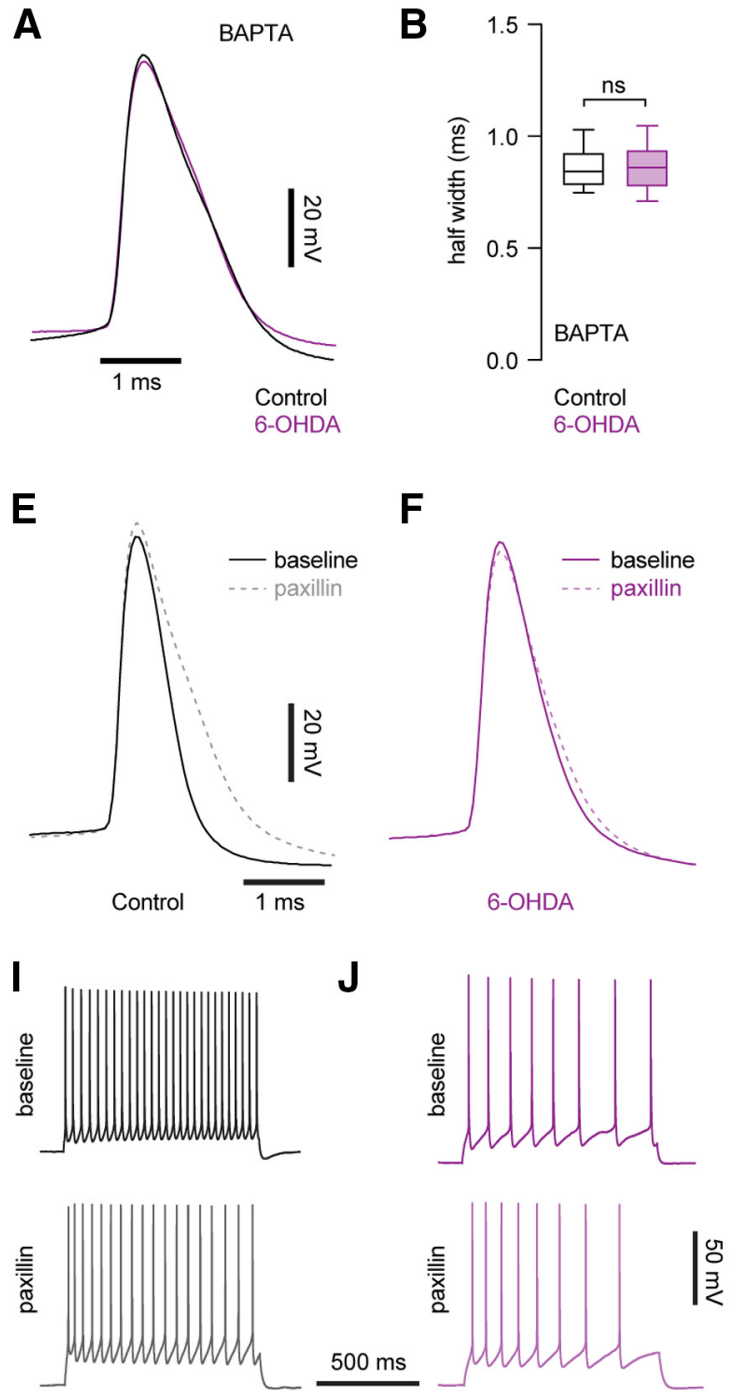
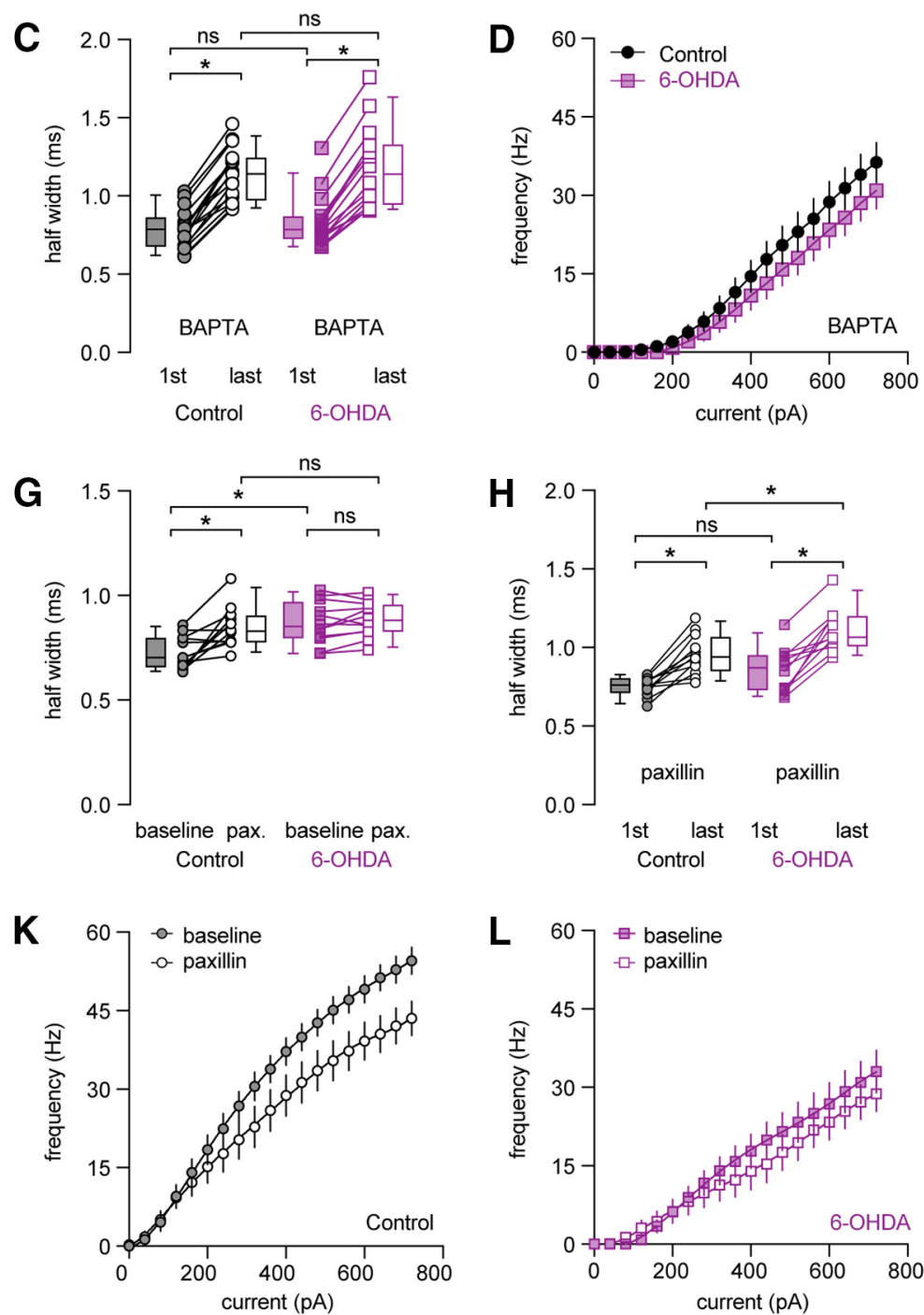

Figure 7. Decreased BK channel activity underlies AP broadening and impaired intrinsic excitability of PTNs following loss of midbrain DA neurons. $A$, Representative AP waveforms of PTNs from controls and 6-OHDA mice in the presence of BAPTA. APs were aligned at the threshold and overlaid for comparison. B, Box plot showing AP width of PTNs at rheobase from controls and 6 OHDA mice in the presence of BAPTA. C, Boxplot showing AP broadening during repetitive firing of PTNs in controls and 6-OHDA mice in the presence of BAPTA. D, Frequency-current curve of PTNs in controls and 6-OHDA mice in the presence of BAPTA. $\boldsymbol{E}, \boldsymbol{F}$, Representative AP waveforms at rheobase before and after paxillin application in PTNs from controls $(\boldsymbol{E})$ and 6-0HDA mice $(\boldsymbol{F})$. APs were aligned at the threshold and overlaid for comparison. $\boldsymbol{G}$, Summarized graph showing paxillin broadened APs of PTNs from both controls and 6-OHDA mice. $\boldsymbol{H}$, Summarized graph showing AP broadening during repetitive firing of PTNs from controls and 6-OHDA mice in the presence of paxillin. $I, J$, Representative AP traces of PTNs from controls and 6-OHDA mice in the absence and presence of paxillin. $\boldsymbol{K}, \boldsymbol{L}$, Frequency-current curves showing paxillin decreased the frequency of PTNs firing om controls, but not in 6-OHDA mice; ${ }^{*} p<0.05$, ns, not significant, WSR or MWU tests.

Further, PTNs in 6-OHDA mice exhibited stronger activitydependent AP broadening during repetitive firing relative to those from controls (Fig. 5D). However, we found that inhibition of BK activity using paxillin abolished difference in the width of the first AP of PTNs (the width of the first AP in paxillin, control $=0.76[0.71,0.8] \mathrm{ms}, 6-\mathrm{OHDA}=0.87[0.73,0.95] \mathrm{ms}$, $p=0.1$, MWU; Fig. $7 H$ ), but did not affect the robust AP broadening during repetitive firing in 6-OHDA mice relative to that in controls (the width of the last AP in paxillin, control $=0.94[0.85$, $1.06] \mathrm{ms}, 6-\mathrm{OHDA}=1.06[1.0,1.2] \mathrm{ms}, p=0.01, n=12$ neurons/ 3 mice for each group; Fig. $7 H$ ). These results suggest that an unidentified ionic conductance, other than BK channels, also contributes to the activity-dependent AP broadening of PTNs in both controls and 6-OHDA mice, which may play a dominant role in parkinsonian state.

Last, we tested whether BK channel dysfunction contributes to the impaired excitability of PTNs in parkinsonism. In agreement with its role in AP repolarization, blockade of BK channels by paxillin decreased the excitability of PTNs in controls (spike numbers at the maximal current injection, baseline $=55[49,59]$, paxillin $=44[36,55], n=12$ neurons $/ 3$ mice, $p=0.0015$, WSR; Fig. $7 I, K$ ), but not in 6-OHDA mice (baseline $=37$ [20, 47], paxillin $=30[21,40], n=12$ neurons $/ 3$ mice, $p=0.12$, WSR; Fig. $7 J, L)$. However, paxillin did not abolish the difference in the firing frequency of PTNs between groups (maximal firing frequency, before paxillin $p=0.0002$ between groups, after paxillin, $p=0.0047, \mathrm{MWU})$, suggesting BK channels dysfunction partially contributes to the decreased intrinsic excitability of PTNs in parkinsonism.

\section{DA cannot recue the decreased intrinsic excitability of PTNs in parkinsonism}

M1 receives dopaminergic inputs from the ventral tegmental area and these neurons are partially degenerate in 6-OHDA mice (Hosp et al., 2011, 2015; Hosp and Luft, 2013). Next, we tested whether a disrupted mesocortical DA neuromodulation 


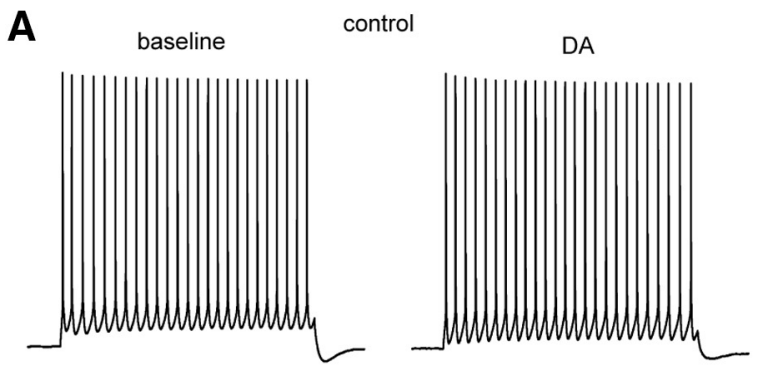

B

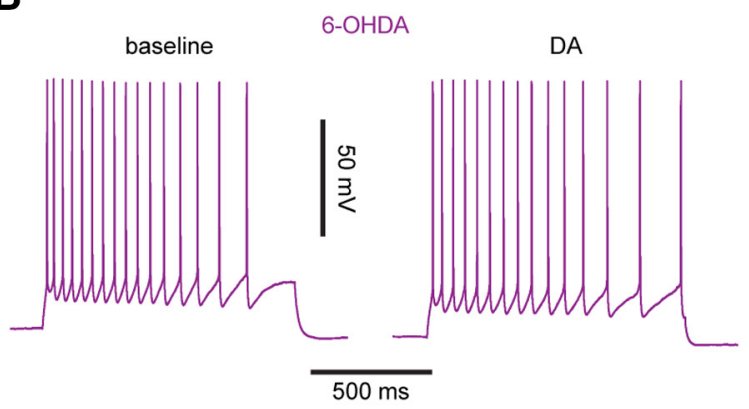

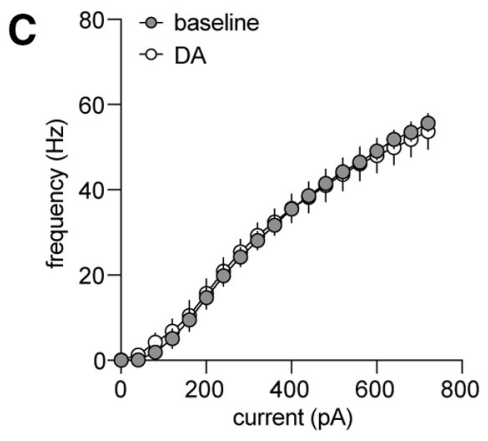
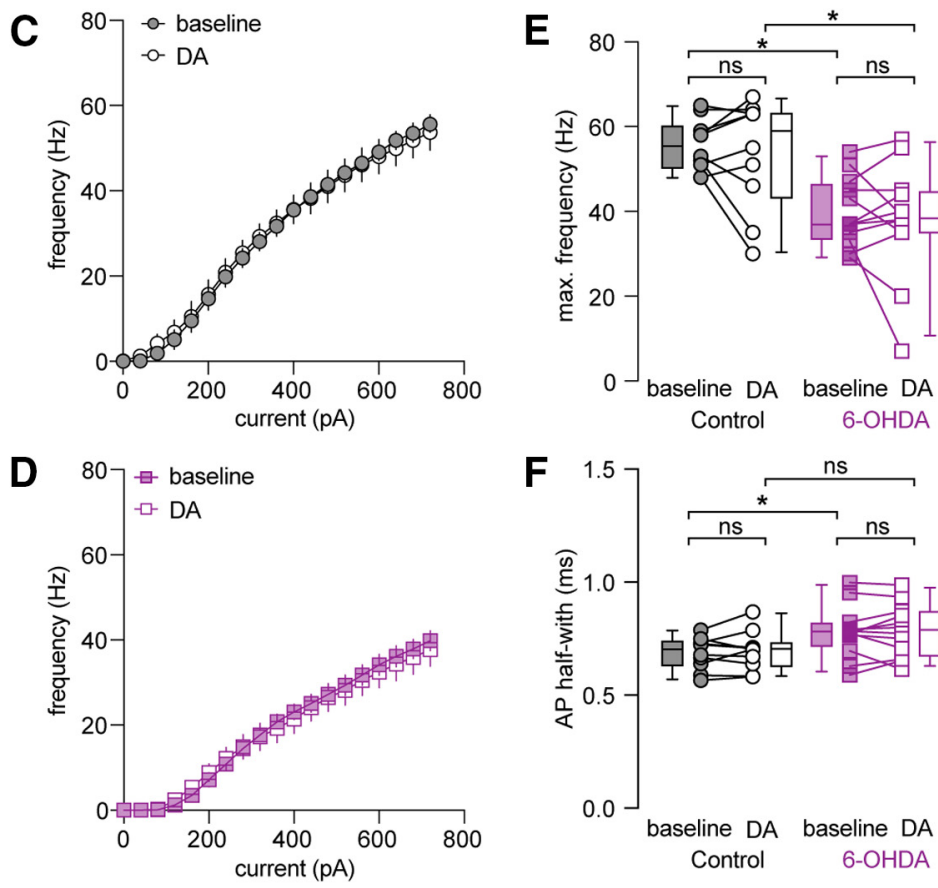

Figure 8. DA application could not rescue the decreased excitability of PTNs following loss of midbrain DA neurons. $A, B$, Representative AP traces of PTNs from controls and 6-0HDA mice in the absence and presence of DA. $\boldsymbol{C}, \boldsymbol{D}$, Frequency-current curves of PTNs from controls $(\boldsymbol{C})$ and 6-0HDA mice $(\boldsymbol{D})$ in the absence and presence of DA. $\boldsymbol{E}$, Summarized graphs showing the lack of impact of DA on maximal firing frequency of PTNs from controls and 6-OHDA mice. $\boldsymbol{F}$, Summarized graphs showing the lack of impact of DA on AP width of PTNs from controls and 6-OHDA mice; ns, not significant; ${ }^{*} p<0.05$, WSR or MWU tests.

contributes to the intrinsic adaptations of PTNs in M1. DA receptors on PTNs were activated through bath perfusion of DA $(10 \mu \mathrm{M})$. However, activation of DA receptors produced negligible effects to the intrinsic excitability of M1 PTNs in controls (e.g., the maximal firing frequency, baseline $=56[50,60] \mathrm{Hz}$; $\mathrm{DA}=59[43,63] \mathrm{Hz} ; n=10$ neurons/3 mice; $p=0.9$, WSR; Fig. $8 A, C, E)$. In addition, application of DA $(10 \mu \mathrm{M})$ did not produce significant effects to the intrinsic excitability of M1 PTNs in 6-OHDA mice either (e.g., the maximal firing frequency, baseline $=37[34,47] \mathrm{Hz}, \mathrm{DA}=39[35,45] \mathrm{Hz}, n=12$ neurons $/ 3$ mice; $p=0.7$, WSR; Fig. $8 B, D, E)$. Further, we found that DA (10 $\mu \mathrm{M})$ did not alter the AP width of PTNs in both groups either (controls: baseline $=0.7[0.63,0.74] \mathrm{ms}, \mathrm{DA}=0.7[0.62,0.73] \mathrm{ms}$, $n=10$ neurons $/ 3$ mice, $p=0.77$, WSR; 6-OHDA: baseline $=0.78$ $[0.71,0.82] \mathrm{ms}, 6-O H D A$ DA $=0.79[0.67,0.87] \mathrm{ms}, n=12$ neurons $/ 3$ mice, $p=0.8$, WSR; Fig. $8 F$ ). These data suggested that restoration of local DA neuromodulation cannot rescue the impaired intrinsic excitability and AP broadening of M1 PTNs following the loss of midbrain DA neurons.

\section{Discussion}

We studied changes in the intrinsic properties of M1 pyramidal neurons in experimental parkinsonism. We found a cell typespecific decrease of the intrinsic excitability of M1 PTNs, but not the ITNs, in parkinsonism. We demonstrated that impaired persistent $\mathrm{Na}^{+}$channel function led to an elevated AP threshold and played a major role in the decreased intrinsic excitability of M1 PTNs. In addition, M1 PTNs also exhibited broadened APs, which partially contributes to the decreased excitability of PTNs during repetitive firing. Further, we revealed that impaired BK channel function contributes to the broadened APs of M1 PTNs in parkinsonism. Last, we showed that the decreased intrinsic excitability of M1 PTNs was not reversible by the acute activation of dopaminergic receptors. Our findings strongly suggest that the loss of midbrain DA neurons not only alters basal ganglia activity, but also triggers intrinsic adaptations in M1 circuitry, which contribute to the pathophysiology of parkinsonism.

Cell type-specific changes in spontaneous activity of M1 pyramidal neurons were first reported in MPTP-treated primates by Pasquereau and Turner (2011). In their excellent work, the authors demonstrated a decreased firing rate and an increased firing irregularity of spontaneous activity of antidromically identified PTNs; in contrast, the firing rate and pattern of corticostriatal neurons were largely intact in MPTP-treated monkeys (Pasquereau and Turner, 2011). Given the different anatomic projections and function of M1 neuron subtypes in motor control, these subtype-specific changes in neuronal activity have great implications in understanding of pathophysiology of parkinsonian motor signs. However, few studies have been conducted to understand the cellular and synaptic mechanisms underlying those changes in M1 neuronal activities in parkinsonism. To address this question, we employed ex vivo electrophysiology to study the intrinsic properties of projection-defined M1 pyramidal neurons in parkinsonism. Following chronic midbrain DA degeneration, PTNs, but not the ITNs, in the L5b of M1 showed decreased intrinsic excitability and this finding is consistent with the earlier findings in MPTP-treated primates (Pasquereau and Turner, 2011). Given the innervation of subcortical motor centers by M1 PTNs, these results suggested that intrinsic adaptations of M1 pyramidal neurons contribute to an insufficient motor cortical outputs in parkinsonism, in addition to an elevated basal ganglia inhibition as proposed by the classical model (Albin et al., 1989; DeLong, 1990; Galvan and Wichmann, 2008). Thus, we propose that these adaptations are important aspects of pathophysiology of parkinsonism.

The decreased excitability of PTNs in 6-OHDA mice associated with a depolarized AP threshold and could be normalized 
by $I_{\mathrm{NaP}}$ blockade using low concentration of TTX. These results, together with the disrupted AP rising kinetics of PTNs in 6-OHDA mice, suggest that an impaired $I_{\mathrm{NaP}}$ function decreases the availability of $\mathrm{Na}_{\mathrm{T}}$ channels that underlie AP depolarization and further promotes their inactivation during repetitive firing, leading to the decreased excitability of PTNs. We posit that the decreased intrinsic excitability makes neurons are more sensitive to synaptic inputs, as that occurs in basal ganglia neurons in parkinsonism (Wilson, 2013). Thus, it is likely that the increased bursting pattern of activity of PTNs in vivo can be largely triggered by synaptic inputs, but the enhanced spike adaptation leads to a reduced intraburst frequency in MPTP-treated monkeys (Pasquereau and Turner, 2011; Pasquereau et al., 2016). Further studies will be needed to determine how synaptic inputs shape M1 neuronal activity in parkinsonism.

APs were significantly broadened in PTNs of parkinsonian animals (Figs. 4A, 5A,B). AP width has significant impact on $\mathrm{Ca}^{2+}$ influx during APs (Bean, 2007), yet functional implications of AP broadening in intracellular $\mathrm{Ca}^{2+}$ dynamics remain unknown. We showed that the AP broadening in PTNs in parkinsonism was partially occluded in the presence of BAPTA and paxillin, indicating a key role of BK channels in AP waveform modulation (Shao et al., 1999; Faber and Sah, 2003; Bean, 2007). It has been proposed that inactivation of $\mathrm{BK}$ channels could reduce $\mathrm{Na}_{T}$ availability for the subsequent AP generation during repetitive firing, leading to a decreased neuronal excitability (Bean, 2007; Jaffe et al., 2011). Consistently, BK inhibition by paxillin strongly decreased excitability of PTNs in controls, but not in 6-OHDA mice, leading to a partial abolishment of the difference in neuronal excitability between groups (Fig. $7 K, L$ ). Thus, we propose that impairments of both $I_{\mathrm{NaP}}$ and BK activities exacerbate progressive accumulation of $\mathrm{Na}_{\mathrm{T}}$ inactivation during repetitive firing, leading to the decreased intrinsic excitability of PTNs in parkinsonism (Fleidervish et al., 1996). It is worthy to note that PTNs in both controls and 6-OHDA mice exhibited activity-dependent AP broadening in the presence of BK inhibition (Fig. 7C,H). It indicates that unidentified ionic channels also contribute to AP repolarization of PTNs (Rudy and McBain, 2001; Pathak et al., 2016; Soares et al., 2017), and their inactivation underlies broadened APs in both groups, but possibly plays a major role in AP repolarization in parkinsonism.

An acute application of DA did not affect the excitability of PTNs in both controls and in 6-OHDA mice. These results are consistent with recent findings that dopaminergic modulation of pyramidal neurons is mainly mediated indirectly by parvalbumin-expressing interneurons in M1 (Vitrac et al., 2014; Cousineau et al., 2020). Alternatively, it is possible that loss of mesocortical dopaminergic modulation contributes to the altered intrinsic excitability of PTNs, but such changes are not reversible by acute dopaminergic receptor activation. Compelling evidence suggests a critical role of dopaminergic modulation in the structural and functional plasticity of the motor cortical circuits (Lindenbach and Bishop, 2013; Ueno et al., 2014; Guo et al., 2015b). Last, circuitry mechanisms may also underlie cellular adaptions in M1 in parkinsonism. For example, recent studies highlighted a critical role of indirect pathway striatal projection neurons in driving cellular and synaptic adaptations in basal ganglia nuclei in parkinsonism, such as the subthalamic nucleus (Chu et al., 2017; Sharott et al., 2017; Ryan et al., 2018; McIver et al., 2019). Similarly, pathologic basal ganglia outputs in parkinsonism can drive adaptive changes in $\mathrm{M} 1$ via the thalamocortical projections (Villalba et al., 2021).
The exaggerated rhythmic activity and aberrant oscillations in the basal ganglia circuitry are closely related to the expression of motor symptoms in PD (Bevan et al., 2002; Little and Brown, 2014). Indeed, the motor cortex exhibits abnormal neural activity in parkinsonian state at both the single-cell and population levels (Goldberg et al., 2002; Pasquereau and Turner, 2011; Pasquereau et al., 2016). Both experimental and computation studies have indicated that cerebral cortical inputs play a crucial role in orchestrating pathologic activity in basal ganglia nuclei (e.g., the external global pallidus and the subthalamic nucleus; Bevan et al., 2002; Magill et al., 2004; Kita and Kita, 2011; Corbit et al., 2016; Chu et al., 2017; Sharott et al., 2017). Recent studies also showed that electrical or optogenetic stimulation of the motor cortical pyramidal neurons and/or their projections produced therapeutic effects in parkinsonian animals (Gradinaru et al., 2009; Li et al., 2012; Sanders and Jaeger, 2016; Magno et al., 2019). Thus, an in-depth understanding of motor cortical adaptations in PD at the cellular and circuitry levels will help to design better therapeutic approaches with fewer off-target effects.

\section{References}

Albin RL, Young AB, Penney JB (1989) The functional anatomy of basal ganglia disorders. Trends Neurosci 12:366-375.

Barthas F, Kwan AC (2017) Secondary motor cortex: where 'sensory' meets 'motor' in the rodent frontal cortex. Trends Neurosci 40:181-193.

Bean BP (2007) The action potential in mammalian central neurons. Nat Rev Neurosci 8:451-465.

Bevan MD, Magill PJ, Terman D, Bolam JP, Wilson CJ (2002) Move to the rhythm: oscillations in the subthalamic nucleus-external globus pallidus network. Trends Neurosci 25:525-531.

Bodor ÁL, Giber K, Rovó Z, Ulbert I, Acsády L (2008) Structural correlates of efficient GABAergic transmission in the basal ganglia-thalamus pathway. J Neurosci 28:3090-3102.

Chu HY, Atherton JF, Wokosin D, Surmeier DJ, Bevan MD (2015) Heterosynaptic regulation of external globus pallidus inputs to the subthalamic nucleus by the motor cortex. Neuron 85:364-376.

Chu HY, McIver EL, Kovaleski RF, Atherton JF, Bevan MD (2017) Loss of hyperdirect pathway cortico-subthalamic inputs following degeneration of midbrain dopamine neurons. Neuron 95:1306-1318.e5.

Contet C, Goulding SP, Kuljis DA, Barth AL (2016) BK channels in the central nervous system. Int Rev Neurobiol 128:281-342.

Corbit VL, Whalen TC, Zitelli KT, Crilly SY, Rubin JE, Gittis AH (2016) Pallidostriatal projections promote $\beta$ oscillations in a dopamine-depleted biophysical network model. J Neurosci 36:5556-5571.

Cousineau J, Lescouzères L, Taupignon A, Delgado-Zabalza L, Valjent E, Baufreton J, Bon-Jégo ML (2020) Dopamine D2-like receptors modulate intrinsic properties and synaptic transmission of parvalbumin interneurons in the mouse primary motor cortex. eNeuro 7:ENEURO.008120.2020 .

DeLong MR (1990) Primate models of movement disorders of basal ganglia origin. Trends Neurosci 13:281-285.

Deng PY, Klyachko VA (2016) Increased persistent sodium current causes neuronal hyperexcitability in the entorhinal cortex of Fmr1 knockout mice. Cell Rep 16:3157-3166.

Ebbesen CL, Brecht M (2017) Motor cortex - to act or not to act? Nat Rev Neurosci 18:694-705.

Ebbesen CL, Doron G, Lenschow C, Brecht M (2017) Vibrissa motor cortex activity suppresses contralateral whisking behavior. Nat Neurosci 20:8289.

Ebbesen CL, Insanally MN, Kopec CD, Murakami M, Saiki A, Erlich JC (2018) More than just a "motor": recent surprises from the frontal cortex. J Neurosci 38:9402-9413.

Economo MN, Viswanathan S, Tasic B, Bas E, Winnubst J, Menon V, Graybuck LT, Nguyen TN, Smith KA, Yao Z, Wang L, Gerfen CR, Chandrashekar J, Zeng H, Looger LL, Svoboda K (2018) Distinct descending motor cortex pathways and their roles in movement. Nature 563:79-84. 
Faber ESL, Sah P (2003) Ca2+-activated K+ (BK) channel inactivation contributes to spike broadening during repetitive firing in the rat lateral amygdala. J Physiol 552:483-497.

Fieblinger T, Graves SM, Sebel LE, Alcacer C, Plotkin JL, Gertler TS, Chan CS, Heiman M, Greengard P, Cenci MA, Surmeier DJ (2014) Cell typespecific plasticity of striatal projection neurons in parkinsonism and LDOPA-induced dyskinesia. Nat Commun 5:5316.

Fleidervish IA, Friedman A, Gutnick MJ (1996) Slow inactivation of $\mathrm{Na}+$ current and slow cumulative spike adaptation in mouse and guinea-pig neocortical neurones in slices. J Physiol 493:83-97.

Galvan A, Wichmann T (2008) Pathophysiology of parkinsonism. Clin Neurophysiol 119:1459-1474.

Gittis AH, Hang GB, LaDow ES, Shoenfeld LR, Atallah BV, Finkbeiner S, Kreitzer AC (2011) Rapid target-specific remodeling of fast-spiking inhibitory circuits after loss of dopamine. Neuron 71:858-868.

Goldberg JA, Boraud T, Maraton S, Haber SN, Vaadia E, Bergman H (2002) Enhanced synchrony among primary motor cortex neurons in the 1-Methyl-4-Phenyl-1,2,3,6-Tetrahydropyridine primate model of Parkinson's disease. J Neurosci 22:4639-4653.

Gradinaru V, Mogri M, Thompson KR, Henderson JM, Deisseroth K (2009) Optical deconstruction of parkinsonian neural circuitry. Science 324:354-359.

Guo JZ, Graves AR, Guo WW, Zheng J, Lee A, Rodríguez-González J, Li N, Macklin JJ, Phillips JW, Mensh BD, Branson K, Hantman AW (2015a) Cortex commands the performance of skilled movement. Elife 4:e10774.

Guo L, Xiong H, Kim J-I, Wu Y-W, Lalchandani RR, Cui Y, Shu Y, Xu T, Ding JB (2015b) Dynamic rewiring of neural circuits in the motor cortex in mouse models of Parkinson's disease. Nat Neurosci 18:1299-1309.

de Hemptinne HC, Swann NC, Ostrem JL, Ryapolova-Webb ES, Luciano MS, Galifianakis NB, Starr PA (2015) Therapeutic deep brain stimulation reduces cortical phase-amplitude coupling in Parkinson's disease. Nat Neurosci 18:779-786.

Hosp JA, Luft AR (2013) Dopaminergic meso-cortical projections to M1: role in motor learning and motor cortex plasticity. Front Neurol 4:145.

Hosp JA, Pekanovic A, Rioult-Pedotti MS, Luft AR (2011) Dopaminergic projections from midbrain to primary motor cortex mediate motor skill learning. J Neurosci 31:2481-2487.

Hosp JA, Nolan HE, Luft AR (2015) Topography and collateralization of dopaminergic projections to primary motor cortex in rats. Exp Brain Res 233:1365-1375.

Jaffe DB, Wang B, Brenner R (2011) Shaping of action potentials by type I and type II large-conductance $\mathrm{Ca} 2+$-activated $\mathrm{K}+$ channels. Neuroscience 192:205-218.

Kawai R, Markman T, Poddar R, Ko R, Fantana AL, Dhawale AK, Kampff AR, Ölveczky BP (2015) Motor cortex is required for learning but not for executing a motor skill. Neuron 86:800-812.

Kita H, Kita T (2011) Cortical stimulation evokes abnormal responses in the dopamine-depleted rat basal ganglia. J Neurosci 31:10311-10322.

Kress GJ, Yamawaki N, Wokosin DL, Wickersham IR, Shepherd GMG, Surmeier DJ (2013) Convergent cortical innervation of striatal projection neurons. Nat Neurosci 16:665-667.

Lee J, Wang W, Sabatini BL (2020) Anatomically segregated basal ganglia pathways allow parallel behavioral modulation. Nat Neurosci 23:13881311.

Li Q, Ke Y, Chan DCW, Qian Z-M, Yung KKL, Ko H, Arbuthnott GW, Yung W-H (2012) Therapeutic deep brain stimulation in parkinsonian rats directly influences motor cortex. Neuron 76:1030-1041.

Lindenbach D, Bishop C (2013) Critical involvement of the motor cortex in the pathophysiology and treatment of Parkinson's disease. Neurosci Biobehav Rev 37:2737-2750.

Little S, Brown P (2014) The functional role of beta oscillations in Parkinson's disease. Parkinsonism Relat Disord 20 [Suppl 1]:S44-S48.

Magill PJ, Sharott A, Bevan MD, Brown P, Bolam JP (2004) Synchronous unit activity and local field potentials evoked in the subthalamic nucleus by cortical stimulation. J Neurophysiol 92:700-714.

Magno LAV, Tenza-Ferrer H, Collodetti M, Aguiar MFG, Rodrigues APC, da Silva RS, Silva JDP, Nicolau NF, Rosa DVF, Birbrair A, Miranda DM, Romano-Silva MA (2019) Optogenetic stimulation of the M2 cortex reverts motor dysfunction in a mouse model of Parkinson's disease. J Neurosci 39:3234-3248.

Mallet N, Pogosyan A, Sharott A, Csicsvari J, Bolam JP, Brown P, Magill PJ (2008) Disrupted dopamine transmission and the emergence of exaggerated beta oscillations in subthalamic nucleus and cerebral cortex. J Neurosci 28:4795-4806.

Mathai A, Ma Y, Paré J-F, Villalba RM, Wichmann T, Smith Y (2015) Reduced cortical innervation of the subthalamic nucleus in MPTPtreated parkinsonian monkeys. Brain 138:946-962.

McGregor MM, Nelson AB (2019) Circuit mechanisms of Parkinson's disease. Neuron 101:1042-1056.

McIver EL, Atherton JF, Chu H-Y, Cosgrove KE, Kondapalli J, Wokosin D, Surmeier DJ, Bevan MD (2019) Maladaptive downregulation of autonomous subthalamic nucleus activity following the loss of midbrain dopamine neurons. Cell Rep 28:992-1002.e4.

Milescu LS, Yamanishi T, Ptak K, Smith JC (2010) Kinetic properties and functional dynamics of sodium channels during repetitive spiking in a slow pacemaker neuron. J Neurosci 30:12113-12127.

Oswald MJ, Tantirigama MLS, Sonntag I, Hughes SM, Empson RM (2013) Diversity of layer 5 projection neurons in the mouse motor cortex. Front Cell Neurosci 7:174.

Parker PRL, Lalive AL, Kreitzer AC (2016) Pathway-specific remodeling of thalamostriatal synapses in parkinsonian mice. Neuron 89:734-740.

Parker JG, Marshall JD, Ahanonu B, Wu YW, Kim TH, Grewe BF, Zhang Y, Li JZ, Ding JB, Ehlers MD, Schnitzer MJ (2018) Diametric neural ensemble dynamics in parkinsonian and dyskinetic states. Nature 557:177-182.

Pasquereau B, Turner RS (2011) Primary motor cortex of the parkinsonian monkey: differential effects on the spontaneous activity of pyramidal tract-type neurons. Cereb Cortex 21:1362-1378.

Pasquereau B, DeLong MR, Turner RS (2016) Primary motor cortex of the parkinsonian monkey: altered encoding of active movement. Brain 139:127-143.

Pathak D, Guan D, Foehring RC (2016) Roles of specific Kv channel types in repolarization of the action potential in genetically identified subclasses of pyramidal neurons in mouse neocortex. J Neurophysiol 115:23172329.

Rudy B, McBain CJ (2001) Kv3 channels: voltage-gated K+ channels designed for high-frequency repetitive firing. Trends Neurosci 24:517526.

Ryan MB, Bair-Marshall C, Nelson AB (2018) Aberrant striatal activity in parkinsonism and levodopa-induced dyskinesia. Cell Rep 23:3438-3446. e5.

Sanders TH, Jaeger D (2016) Optogenetic stimulation of cortico-subthalamic projections is sufficient to ameliorate bradykinesia in 6-ohda lesioned mice. Neurobiol Dis 95:225-237.

Sauerbrei BA, Guo J-Z, Cohen JD, Mischiati M, Guo W, Kabra M, Verma N, Mensh B, Branson K, Hantman AW (2020) Cortical pattern generation during dexterous movement is input-driven. Nature 577:386-391.

Shao L, Halvorsrud R, Borg-Graham L, Storm JF (1999) The role of BK-type $\mathrm{Ca} 2+$-dependent $\mathrm{K}+$ channels in spike broadening during repetitive firing in rat hippocampal pyramidal cells. J Physiol 521:135-146.

Sharott A, Vinciati F, Nakamura KC, Magill PJ (2017) A population of indirect pathway striatal projection neurons is selectively entrained to parkinsonian beta oscillations. J Neurosci 37:9977-9998.

Sheets PL, Suter BA, Kiritani T, Chan CS, Surmeier DJ, Shepherd GMG (2011) Corticospinal-specific HCN expression in mouse motor cortex: I (h)-dependent synaptic integration as a candidate microcircuit mechanism involved in motor control. J Neurophysiol 106:2216-2231.

Shen W, Plotkin JL, Francardo V, Ko WKD, Xie Z, Li Q, Fieblinger T, Wess J, Neubig RR, Lindsley CW, Conn PJ, Greengard P, Bezard E, Cenci MA, Surmeier DJ (2015) M4 muscarinic receptor signaling ameliorates striatal plasticity deficits in models of L-DOPA-induced dyskinesia. Neuron 88:762-773.

Shepherd GMG (2013) Corticostriatal connectivity and its role in disease. Nat Rev Neurosci 14:278-291.

Shimamoto SA, Ryapolova-Webb ES, Ostrem JL, Galifianakis NB, Miller KJ, Starr PA (2013) Subthalamic nucleus neurons are synchronized to primary motor cortex local field potentials in Parkinson's disease. J Neurosci 33:7220-7233.

Soares D, Goldrick I, Lemon RN, Kraskov A, Greensmith L, Kalmar B (2017) Expression of $\mathrm{Kv} 3.1 \mathrm{~b}$ potassium channel is widespread in macaque motor cortex pyramidal cells: a histological comparison between rat and macaque. J Comp Neurol 525:2164-2174.

Sreenivasan V, Esmaeili V, Kiritani T, Galan K, Crochet S, Petersen CCH (2016) Movement initiation signals in mouse whisker motor cortex. Neuron 92:1368-1382. 
Suter BA, Migliore M, Shepherd GMG (2013) Intrinsic electrophysiology of mouse corticospinal neurons: a class-specific triad of spike-related properties. Cereb Cortex 23:1965-1977.

Ueno T, Yamada J, Nishijima H, Arai A, Migita K, Baba M, Ueno S, Tomiyama M (2014) Morphological and electrophysiological changes in intratelencephalic-type pyramidal neurons in the motor cortex of a rat model of levodopa-induced dyskinesia. Neurobiol Dis 64:142-149.

Viaro R, Morari M, Franchi G (2011) Progressive motor cortex functional reorganization following 6-hydroxydopamine lesioning in rats. J Neurosci 31:4544-4554.

Vila M, Périer C, Féger J, Yelnik J, Faucheux B, Ruberg M, Raisman-Vozari R, Agid Y, Hirsch EC (2000) Evolution of changes in neuronal activity in the subthalamic nucleus of rats with unilateral lesion of the substantia nigra assessed by metabolic and electrophysiological measurements. Eur J Neurosci 12:337-344.

Villalba RM, Behnke JA, Pare JF, Smith Y (2021) Comparative ultrastructural analysis of thalamocortical innervation of the primary motor cortex and supplementary motor area in control and MPTP-treated parkinsonian monkeys. Cereb Cortex. Advance online publication. Retrieved March 2, 2021. doi: $10.1093 /$ cercor/bhab020.

Villalobos C, Shakkottai VG, Chandy KG, Michelhaugh SK, Andrade R (2004) SKCa channels mediate the medium but not the slow calciumactivated afterhyperpolarization in cortical neurons. J Neurosci 24:35373542.

Vitrac C, Péron S, Frappé I, Fernagut P-O, Jaber M, Gaillard A, BenoitMarand M (2014) Dopamine control of pyramidal neuron activity in the primary motor cortex via D2 receptors. Front Neural Circuit 8:14.

Wang X, Liu Y, Li X, Zhang Z, Yang H, Zhang Y, Williams PR, Alwahab NSA, Kapur K, Yu B, Zhang Y, Chen M, Ding H, Gerfen CR, Wang KH, He Z (2017) Deconstruction of corticospinal circuits for goal-directed motor skills. Cell 171:440-455.e14.

Willard AM, Isett BR, Whalen TC, Mastro KJ, Ki CS, Mao X, Gittis AH (2019) State transitions in the substantia nigra reticulata predict the onset of motor deficits in models of progressive dopamine depletion in mice. Elife 8:e42746.

Wilson CJ (2013) Active decorrelation in the basal ganglia. Neuroscience 250:467-482. 